\title{
Metabolic determinants of the immune modulatory function of neural stem cells
}

Denise Drago ${ }^{1,7^{*}}$, Veronica Basso ${ }^{2}$, Edoardo Gaude ${ }^{3}$, Giulio Volpe ${ }^{7}$, Luca Peruzzotti-Jametti ${ }^{7}$, Angela Bachi ${ }^{4}$, Giovanna Musco ${ }^{5}$, Annapaola Andolfo ${ }^{6}$, Christian Frezza ${ }^{3}$, Anna Mondino ${ }^{2}$ and Stefano Pluchino ${ }^{7 *}$

\begin{abstract}
Background: Neural stem cells (NSCs) display tissue trophic and immune modulatory therapeutic activities after transplantation in central nervous system disorders. The intercellular interplay between stem cells and target immune cells is increased in NSCs exposed to inflammatory cues. Here, we hypothesize that inflammatory cytokine signalling leads to metabolic reprogramming of NSCs regulating some of their immune modulatory effects.

Methods: NSC lines were prepared from the subventricular zone (SVZ) of 7-12-week-old mice. Whole secretomebased screening and analysis of intracellular small metabolites was performed in NSCs exposed to cocktails of either Th1-like (IFN- $\gamma, 500 \mathrm{U} / \mathrm{ml}$; TNF-a, $200 \mathrm{U} / \mathrm{ml} ; \mathrm{IL}-1 \beta, 100 \mathrm{U} / \mathrm{ml}$ ) or Th2-like (IL-4, IL-5 and IL-13; $10 \mathrm{ng} / \mathrm{ml}$ ) inflammatory cytokines for $16 \mathrm{~h}$ in vitro. Isotopologues distribution of arginine and downstream metabolites was assessed by liquid chromatography/mass spectrometry in NSCs incubated with $\mathrm{U}^{13} \mathrm{C}_{6} \mathrm{~L}$-arginine in the presence or absence of Th1 or Th2 cocktails (Th1 NSCs or Th2 NSCs). The expression of arginase I and II was investigated in vitro in Th1 NSCs and Th2 NSCs and in vivo in the SVZ of mice with experimental autoimmune encephalomyelitis, as prototypical model of Th1 cell-driven brain inflammatory disease. The effects of the inflammatory cytokine signalling were studied in NSC-lymph node cells (LNC) co-cultures by flow cytometry-based analysis of cell proliferation following pan-arginase inhibition with $\mathrm{N}^{\omega}$-hydroxy-nor-arginine (nor-NOHA).
\end{abstract}

Results: Cytokine-primed NSCs showed significantly higher anti-proliferative effect in co-cultures vs. control NSCs. Metabolomic analysis of intracellular metabolites revealed alteration of arginine metabolism and increased extracellular arginase I activity in cytokine-primed NSCs. Arginase inhibition by nor-NOHA partly rescued the antiproliferative effects of cytokine-primed NSCs.

Conclusions: Our work underlines the use of metabolic profiling as hypothesis-generating tools that helps unravelling how stem cell-mediated mechanisms of tissue restoration become affected by local inflammatory responses. Among different therapeutic candidates, we identify arginase signalling as novel metabolic determinant of the NSC-to-immune system communication.

Keywords: Metabolomics, Neural stem cells, Immune modulation, Lymph node cells, Arginase I

Abbreviations: BSTFA, Bistrimethyl-silyl-triflouroacetamide; CFSE, 5-(and-6)-carboxyfluorescein diacetate succinimidyl ester; CGM, Complete growth medium; DAPI, 4,6-diamidino-2-phenylindole; DCs, Dendritic cells; dpi, Days post immunization; EAE, Experimental autoimmune encephalomyelitis; EDTA, Ethylenediaminetetraacetic acid;

(Continued on next page)

\footnotetext{
*Correspondence: drago.denise@hsr.it; spp24@cam.ac.uk

${ }^{1}$ CNS Repair Unit, Institute of Experimental Neurology (INSPE), Division of

Neurosciences, San Raffaele Scientific Institute, 20132 Milan, Italy

${ }^{7}$ Department of Clinical Neurosciences, Wellcome Trust-Medical Research

Council Stem Cell Institute and National Institute for Health Research

Biomedical Research Centre, University of Cambridge, Hills Road, CB2 OHA

Cambridge, UK

Full list of author information is available at the end of the article
}

(c) 2016 The Author(s). Open Access This article is distributed under the terms of the Creative Commons Attribution 4.0 International License (http://creativecommons.org/licenses/by/4.0/), which permits unrestricted use, distribution, and reproduction in any medium, provided you give appropriate credit to the original author(s) and the source, provide a link to the Creative Commons license, and indicate if changes were made. The Creative Commons Public Domain Dedication waiver (http://creativecommons.org/publicdomain/zero/1.0/) applies to the data made available in this article, unless otherwise stated. 


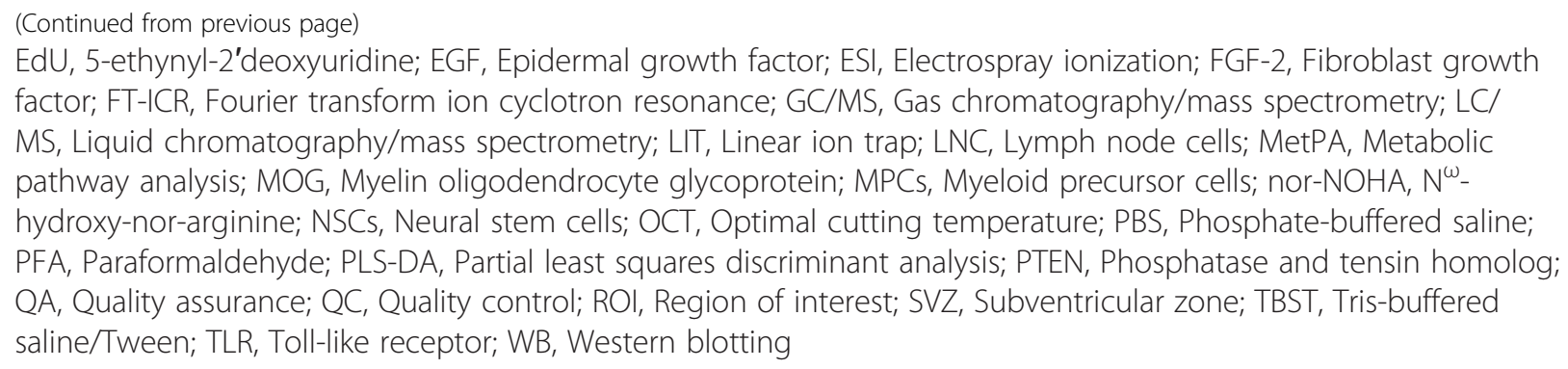

\section{Background}

Compelling evidence is available that transplanted stem cells promote significant clinico-pathological recovery in several preclinical models of neurological disorders such as multiple sclerosis, cerebral stroke and spinal cord injury [1-4].

Remarkable neuroprotective and immune modulatory capacities have been identified for neural stem cells (NSCs) that may result from consistent mechanisms of intercellular interplay with target host cells and may predominantly account for the therapeutic effects of NSC grafts [2, 5-9]. The putative mechanisms that sustain both repair capabilities, as well as long-term functional integration of NSCs upon transplantation, are yet to be fully understood.

Rodent NSCs inhibit the activation and proliferation of antigen-specific and antigen non-specific Th1 and Th17 cells in vitro, as well as promote $\mathrm{T}$ cell apoptosis [6, 9-11]. Human NSCs suppress the proliferation and alter the profile of cytokine secretion of xenogeneic antigen-specific and allogeneic mitogen-activated $\mathrm{T}$ cells $[12,13]$. Compared to rodent NSCs, human NSCs have a lower cytotoxicity towards $\mathrm{T}$ cells but a higher cytotoxicity towards monocyte/macrophages in vitro [14]. Human NSCs also hinder the differentiation of myeloid precursor cells (MPCs) into immature dendritic cells (DCs), and the maturation of immature DCs to functional antigen-presenting cells [13]. Recent studies have also shed new light on the understanding of mechanisms of transcellular information exchange and demonstrated that cytokine-regulated exosome signalling is an important pathway by which NSCs exploit some of their protective capacities [15]. In parallel to these functional studies, the investigation of the stem cell secretome has gained increasing attention in recent years because of its multiple implications for the potential reparative, restorative, or regenerative applications of stem cell medicines [16-19]. Paracrine signalling mediated by stem cells plays an essential role in the reparative process observed after stem cells transplantation, with stem cells secreting growth factors, chemokines and cytokines, both constitutively as well as in response to priming with proinflammatory molecules $[17,18,20-23]$.
Thus, the concept that stem cells solely act as directly repairing cells is now being revisited and enriched with the emerging view that stem cells secrete certain regenerative factors in response to environmental stimuli, which include cytokines, growth factors, morphogens and toll-like receptor (TLR) ligands [16, 24]. Hypoxic preconditioning, exposure to inflammatory cytokines or mechanical and shear stress conditioning (e.g. growing cells in 3D spheres or scaffolds) have all been shown to promote the release of different potential therapeutic small molecules [24, 25].

The ability of stem cells to secrete neuroprotective and immune modulatory factors indicates that there is still a lot to learn about functional stem cell plasticity, especially when the regulation of host responses is enhanced after licensing or priming with inflammatory cytokines such as for NSCs [21].

Metabolomics is a promising complementary approach to explore the functional stem cell response to cellular signalling and is defined as the metabolic complement of functional genomics. Metabolomics enables the systematic analysis of small metabolites involved in biochemical reactions, revealing connections between different pathways that operate within living cells [26-30]. The identity, concentration and fluxes of metabolites are the final product of interactions between gene expression, protein expression and the cellular environment. Thus, metabolomics amplifies changes both in the proteome and the genome and represents a more accurate approximation to the phenotype of an organism in health and disease [31,32].

We exploited metabolomics to investigate whether cytokine signalling leads to metabolic reprogramming of NSCs driving some of their immune modulatory effects.

To this aim, we sought to measure small molecules from undifferentiated mouse NSCs and anticipated that these compounds were altered in NSCs primed with inflammatory cytokines. Whole secretome-based screening and analysis of intracellular small metabolites were performed in NSCs after exposure to a cocktail of Th1like or Th2-like inflammatory cytokines as in vitro system mimicking the putative inflammatory niche that has been described to induce an immune modulatory phenotype in stem cells in vivo [3]. 
Our high-throughput omic approach defined the arginine metabolism to be mostly altered in Th1 NSCs. In parallel, we found that NSCs constitutively expressed both intracellular arginase II and extracellular arginase I, while arginase inhibition by $\mathrm{N}^{\omega}$-hydroxy-nor-arginine (nor-NOHA) blocked some of the immune modulatory effects of Th1 NSCs.

Our work underlines the use of the NSC metabolome as a hypothesis-generating tool for the identification of candidate biomarkers that will predict or measure pharmacological efficacy or toxic responses. It also identifies arginase signalling as a novel metabolic determinant of the NSC-to-immune system communication to be exploited in the manipulation of the NSC activities in therapeutic settings.

\section{Methods}

\section{NSC preparations}

NSCs lines were prepared from the subventricular zone (SVZ) of 7-12-week-old female SJL mice (18-20 gr. Charles River). NSCs were grown in a serum-free basal medium, NeuroCult basal medium plus mouse NeuroCult proliferation supplements (Complete Growth Medium, CGM; Stem Cell Technologies) supplemented with $2 \mu \mathrm{g} /$ $\mathrm{ml}$ heparin (Sigma-Aldrich), $20 \mathrm{ng} / \mathrm{ml}$ purified human recombinant epidermal growth factor (EGF; Provitro) and $10 \mathrm{ng} / \mathrm{ml}$ human recombinant fibroblast growth factor (FGF)-2 (Provitro) [9]. At time of passaging (every 3-5 days), neurospheres were dissociated by enzymatic digestion with Accumax (Sigma) at $37{ }^{\circ} \mathrm{C}$ for $15 \mathrm{~min}$, the number of viable cells determined by trypan blue exclusion and viable cells re-plated at 8000 cells $/ \mathrm{cm}^{2}\left(1.3 \times 10^{6}\right.$ cells with $15-\mathrm{ml}$ media in T162 flask) [33]. NSCs at passage number $\leq 15$ were used in all experiments.

\section{Th1 and Th2 cytokine priming}

NSCs were plated in CGM with or without either Th1like $(200 \mathrm{U} / \mathrm{ml}$ recombinant mouse TNF- $\alpha$, Pepro Tech Inc; $500 \mathrm{U} / \mathrm{ml}$ recombinant mouse IFN- $\gamma$, Pepro Tech Inc; $100 \mathrm{U} / \mathrm{ml}$ recombinant mouse IL-1 $\beta$, Pepro Tech Inc) or Th2-like (10 ng/ml recombinant murine IL-4, R\&D; $10 \mathrm{ng} / \mathrm{ml}$ recombinant mouse IL-5, R\&D; $10 \mathrm{ng} / \mathrm{ml}$ recombinant mouse IL-13, R\&D) cytokine cocktails for $16 \mathrm{~h}$ in vitro [33]. At the end of the conditioning, NSCs were washed three times with phosphate-buffered saline (PBS) to remove cytokine contamination before cell harvesting. Finally, NSCs and NSC-conditioned media were processed according to the analysis to be performed.

\section{Metabolomic analysis by liquid chromatography/mass spectrometry (LC/MS) and gas chromatography/mass spectrometry (GC/MS) \\ Sample preparation}

NSCs were plated at 348,000 cells $/ \mathrm{ml}\left(5.2 \times 10^{6}\right.$ cells with 15 -ml media in T162 flask) in CGM added with either
Th1-like or Th2-like cytokine cocktails as above. Basal, Th1, and Th2 NSCs were harvested ( $10^{7}$ cells per sample), and the supernatants immediately collected to be analysed by using Metabolon platform service. Five biological replicates of NSCs pellets were washed twice with PBS and then snap-frozen on dry ice and stored at $-80{ }^{\circ} \mathrm{C}$ until shipment to Metabolon. The sample preparation process was carried out using the automated MicroLab STAR $^{\circ}$ system from Hamilton Company. Recovery standards were added prior to the first step in the extraction process for quality control (QC) purposes. Sample preparation was conducted using a proprietary series of organic and aqueous extractions to remove the protein fraction while allowing maximum recovery of small molecules. The resulting extract was divided into two fractions: one for analysis by LC and one for analysis by GC. The samples were placed briefly on a TurboVap ${ }^{\oplus}$ (Zymark) to remove the organic solvent. Each sample was then frozen and dried under vacuum. The samples were then prepared for the appropriate instrument, either LC/MS or GC/MS.

\section{Quality assurance (QA)/quality control (QC)}

For quality assurance QA/QC purposes, additional samples were included with each day's analysis. These samples included a well-characterized pool of human plasma, a pool of a small aliquot of each experimental sample, an ultra-pure water process blank and an aliquot of solvents used in extraction to segregate contamination sources in the extraction. Furthermore, a selection of QC compounds was added to every sample, including those under test. These compounds were chosen carefully so as not to interfere with the measurement of the endogenous compounds.

\section{GC/MS}

The samples destined for GC/MS analysis were re-dried under vacuum desiccation for a minimum of $24 \mathrm{~h}$ prior to being derived under dried nitrogen using bistrimethylsilyl-triflouroacetamide (BSTFA). The GC column was $5 \%$ phenyl and the temperature ramp was from 40 to $300{ }^{\circ} \mathrm{C}$ in a 16 -min period. The samples were analysed on a Thermo-Finnigan Trace DSQ fast-scanning singlequadrupole mass spectrometer using electron impact ionization. The instrument was tuned and calibrated for mass resolution and mass accuracy on a daily basis. The information output from the raw data files was automatically extracted as discussed below.

\section{Accurate mass determination and MS/MS fragmentation (LC/MS), (LC/MS/MS)}

The LC/MS portion of the platform was based on a Waters ACQUITY UPLC and a Thermo-Finnigan LTQFT mass spectrometer, which had a linear ion trap (LIT) front end and a Fourier transform ion cyclotron resonance 
(FT-ICR) mass spectrometer back end. For ions with counts greater than two million, an accurate mass measurement could be performed. Accurate mass measurements could be made on the parent ion as well as fragments. The typical mass error was less than $5 \mathrm{ppm}$. Ions with less than two million counts require a greater amount of effort to characterize. Fragmentation spectra (MS/MS) were typically generated in a data-dependent manner, but if necessary, targeted MS/MS could be employed, such as in the case of lower level signals.

\section{Western blotting}

NSCs were plated at 348,000 cells $/ \mathrm{ml}$, collected after $16 \mathrm{~h}$ of incubation in CGM without or with Th1 or Th2 cytokines and washed with PBS. Conditioned media were collected and immediately frozen at $-80{ }^{\circ} \mathrm{C}$ before the protein quantification. Protein quantification was performed using Direct Detect Spectrometer (Millipore). One hundred microgram of total protein for NSCconditioned media were separated by SDS-PAGE using 4-12 \% precast NuPAGE Bis-Tris gels (1.5-mm thickness) under reducing (Reducing Buffer, 10x) conditions and MES running buffer and then transferred onto nitrocellulose membranes $(0.45-\mu \mathrm{m}$ pore size, Hybond ECL) using XCell II Blot Module and NuPAGE transfer buffer (all from Invitrogen). Molecular weight marker: SeeBluePlus2PrestainedStandard (Invitrogen). For immunoblot analysis, the membranes were blocked for $1 \mathrm{~h}$ at room temperature with Tris-buffered saline/Tween (TBST; $10 \mathrm{mM}$ Tris- $\mathrm{HCl}, 150 \mathrm{mM} \mathrm{NaCl}, 0.1 \%$ Tween 20 $\mathrm{pH}$ 7.6) containing $5 \%$ nonfat dry milk and then incubated overnight at $4{ }^{\circ} \mathrm{C}$ with rabbit anti-arginase I (H-52, Santa Cruz Biotech) or anti-arginase II antibody (H-64, Santa Cruz Biotech) by using antibody dilution 1:200. Mouse liver (sc-2256, Santa Cruz) and rat kidney (sc2394, Santa Cruz Biotech) extracts were used as positive control for arginase I and arginase II, respectively. After washing with TBST, the nitrocellulose membranes were incubated with the appropriate donkey anti rabbit IgG HRP antibody (Amersham NA9340V; dilution used: 1:3000) for $1 \mathrm{~h}$ at room temperature. Immunoreactivity was revealed by using an ECL detection kit (Pierce).

\section{Measurement of ${ }^{13} \mathrm{C}$-labelled metabolites by LC/MS}

$1 \times 10^{6}$ cells were plated in T25 flasks and cultured in CGM supplemented with $\mathrm{U}^{13}{ }^{13} \mathrm{C}_{6} \mathrm{~L}$-arginine (Cambridge Isotopes Laboratories) for $2 \mathrm{~h}$ and $16 \mathrm{~h}$ in the absence and in the presence of Th1 and Th2 cytokines cocktails. The cells were then harvested, washed with PBS $(2 \times$ $5 \mathrm{~min}$ ), and lysed for $15 \mathrm{~min}$ at $4{ }^{\circ} \mathrm{C}$ under agitation with $1 \mathrm{ml}$ of $50 \%$ methanol and $30 \%$ acetonitrile in water kept in dry ice/methanol bath $\left(-80{ }^{\circ} \mathrm{C}\right)$. The insoluble material was pelleted in a cooled centrifuge at $14,000 \mathrm{~g}$ for $10 \mathrm{~min}$ at $4{ }^{\circ} \mathrm{C}$ and the supernatant were collected for LC-MS analysis. XBridge Amide column (3.5 $\mu \mathrm{m}$, $150 \times 2.1 \mathrm{~mm}$ ) was used for LC separation and the detection of metabolites was performed using a Thermo Scientific Q-Exactive high-resolution mass spectrometer with electrospray (ESI) ionization, examining metabolites in both positive and negative ion modes, over the mass range of $75-1000 \mathrm{~m} / \mathrm{z}$. The mobile phase for elution was a gradient established between water acidified with $0.1 \%$ formic acid (A) and acetonitrile acidified with $0.1 \%$ formic acid (B) at a flow rate of $200 \mu \mathrm{l} / \mathrm{min}$. The gradient used was preceded by an isocratic step at $20 \% \mathrm{~A} /$ $80 \% \mathrm{~B}$. This step was followed by a linear decrease of B at $20 \%$ in $25 \mathrm{~min}$ and re-equilibration at $20 \% \mathrm{~A} / 80 \%$ B for $11 \mathrm{~min}$. The injected volume was $5 \mu \mathrm{l}$.

\section{Urea cycle colorimetric assay}

$1.74 \times 10^{6}$ cells (cellular density 348,000 cells $/ \mathrm{ml}$ ) were seeded onto T25 flask ( $5 \mathrm{ml}$ medium) in the absence or in the presence of either Th1 or Th2 cytokines cocktails. NSCs at different experimental conditions were homogenized in $100 \mu \mathrm{l}$ Assay Buffer (Urea Assay Colorimetric Kit, Biovision), centrifuged at $15,000 \mathrm{~g}$ for $10 \mathrm{~min}$ to remove insoluble materials. Fifteen-microliter samples were directly added to a 96-well plate for the urea determination according to the manufacturer's instructions.

\section{Arginase enzymatic activity}

The enzymatic activity of arginase within NSCs (with or without Th1 or Th2 cytokines cocktails) was determined by arginase activity colorimetric assay kit (BioVision). Briefly, $1 \times 10^{6}$ cells at the same cellular density used for the metabolomic studies $(348,000$ cells $/ \mathrm{ml})$ were dissolved with $100 \mu \mathrm{l}$ ice-cold arginase buffer and centrifuged at $10,000 \mathrm{~g}$ for $5 \mathrm{~min}$. The supernatants were collected, and $40 \mu \mathrm{l}$ were used to perform the assay for each samples.

\section{NSC/lymph node cell co-culture}

Axillary, brachial, cervical, inguinal, and mesenteric lymph nodes were surgically excised from SJL mice and reduced to single cell suspension by mechanical disruption.

In selected experiments, $\mathrm{CD} 4^{+} \mathrm{T}$ cells were purified by negative selection using anti-CD8 (clone KT1.5) and antiI-Ab-d/I-E (clone B21-22) rat Abs and sheep anti-ratcoated magnetic beads (Dynal Biotech, UK) to a purity of $95 \%$. Purified CD4 lymphocytes or unfractionated lymph node cells $(\mathrm{LNC})$ were seeded in 96 -well plates $\left(1 \times 10^{5}\right.$ per well) in a final volume of $200 \mu$ of CGM and were stimulated with anti-mouse-CD3/CD28 beads (Dynabeads mouse T-activator CD3/CD28, Invitrogen) at a ratio of 1:1 or left untreated. NSCs were pre-conditioned for $16 \mathrm{~h}$ with Th1 or Th2 cytokines cocktails at 348,000 cells/ml and then co-cultured with LNCs (NSC/LNC ratio 1:2) in 
the same well. NSCs were washed three times with PBS to avoid any cytokine carry-over in the co-culture system.

In selected experiments, LNCs were labelled with the vital dye, 5-(and-6)-carboxyfluorescein diacetate succinimidyl ester (CFSE; Molecular Probes, Invitrogen), final concentration of $1 \mu \mathrm{mol} / \mathrm{L}$. Briefly, the cells were washed twice with PBS and suspended at $20 \times 10^{6} / \mathrm{ml}$ in PBS. An equal volume of CFSE at $2 \mu \mathrm{mol} / \mathrm{L}$ was then added. After 8-min incubation under gentle shaking at room temperature, an equal volume of FCS was added to quench the reaction. LNCs were then washed twice in RPMI with $10 \%$ FCS and plated with NSCs in cocultures for 48 and $72 \mathrm{~h}$, as above. LNCs were surface stained with rat anti-mouse CD4 Pacific Blue conjugated (clone RM4-5, BD Pharmingen) and CD44PerCP-Cy5.5 (BioLegend). The nuclear counterstain and dead cell indicator TO-PRO3 Iodide (Molecular Probes) was added before the flow cytometry acquisition. In a parallel coculture experiment, the cells were labelled for the last $5 \mathrm{~h}$ of a 72 -h-long culture with $10 \mu \mathrm{M}$ 5-ethynyl-2' deoxyuridine (EdU). EdU-Click iT Flow Cytometry Assay (Alexa 647, Invitrogen, Molecular Probes) was used to detect EdU incorporation according to the manufacturer's instructions (reaction volumes were adjusted to $50 \mu \mathrm{l})$. LNCs were surface stained with rat anti-mouse CD4 Pacific Blue conjugated (clone RM4-5) and CD44PerCP-Cy5.5.

$\mathrm{N}^{\omega}$-hydroxy-L-arginine (nor-NOHA; $30 \mu \mathrm{M}$ ) was added to cultures to inhibit arginase activity. Flow cytometry was performed with FACSCalibur (BD Biosciences), and a minimum of 15,000 events were acquired. Analysis of FACS data was performed using the FlowJo_V10 software.

\section{Arginase I and II expression on NSCs in vitro}

Analysis of basal and cytokine-induced expression and localization (cytosol vs. mitochondria) of arginase I and II was done on mouse NSCs transduced with a 3rd generation Mito-DsRed lentiviral vector. NSCs were plated in CGM (laminin 1:100) at a density of 80,000 cells $/ \mathrm{cm}^{2}$. After $12 \mathrm{~h}$, the cells were treated for additional $16 \mathrm{~h}$ in vitro with Th1 or Th2 cytokine cocktails as above. Untreated NSCs were used as controls. NSCs were fixed with paraformaldehyde (PFA) $4 \%$ and then stained using a chicken anti-nestin (1:500; Abcam) and a goat anti-arginase I (1:100; Santa Cruz) or a rabbit anti-arginase II (1:100; Santa Cruz) primary antibodies. Appropriate Alexa Fluor conjugated secondary antibodies were then used. Nuclei were counterstained with 4, 6-diamidino-2-phenylindole (DAPI). For the assessment of arginase I and II expression, immunofluorescent staining were evaluated adopting a CCD camera/fluorescent microscope; $n=5$ equally distributed regions of interest (ROIs) were chosen and acquired via $\times 20$ objective lens for analysis $(n=4$ cover slides were used for each group). Fluorescence intensity was calculated with ImageJ Software (NIH) and normalized on the number of DAPI ${ }^{+}$cells/ROI. Data were expressed as arginase I or II mean normalized intensities over micron ${ }^{2} \pm$ SEM.

\section{Arginase I and II expression on NSCs in vivo}

Ex vivo histopathological fluorescent images of ArgI/ArgII expression at level of SVZ were obtained from 4-8-weekold C57BL/6 female mice with myelin oligodendrocyte glycoprotein (MOG) peptide 35-55 induced experimental autoimmune encephalomyelitis (EAE) at 25 and 50 days post immunization (dpi), as described [33]. Strain-, age-, sex- and weight-matched healthy mice were used as controls. The mice were transcardially perfused with saline EDTA and $4 \%$ paraformaldehyde. Brains were removed and post-fixed in PFA $4 \%$ for $24 \mathrm{~h}$ at $4{ }^{\circ} \mathrm{C}$ and then washed with PBS. The brains were cryoprotected with $30 \%$ sucrose (Sigma) and then embedded in optimal cutting temperature (OCT) Tissue Tek compound (EM sciences) for freezing. Twenty five-micrometer-thick coronal brain sections were cut and collected onto SuperfrostPlus slides (Menzel-Glaser, Thermo Fisher Scientific) and processed for histopathology. The following primary antibodies were used: goat anti-arginase I (1:100 Santa Cruz), rabbit anti-arginase II (1:100 Santa Cruz), chicken anti-nestin (1:500 Abcam) and a rat anti-CD45 (BD). Appropriate Alexa Fluor-conjugated secondary antibodies were used. Nuclei were counterstained with DAPI. Confocal microscopy images of SVZ healthy controls and MOG-induced EAE mice were acquired at $\times 40$ and $\times 63$.

\section{Statistical analysis}

Statistically significant differences between experimental groups were determined by Kruskal-Wallis followed by unpaired two-tailed $t$ test (for comparisons between groups). $* /{ }^{\circ} / \wedge p \leq 0.05 ;{ }^{* * / 00} p \leq 0.01 ; * * * p \leq 0.001$ and n.s. $=$ not significant. Statistical analyses were performed using Prism software (v6.0f, GraphPad Software, San Diego, CA).

\section{Results}

In vitro NSCs priming with inflammatory cytokines potentiates their anti-proliferative effect on $\mathrm{T}$ cells

Priming with environmental stimuli that include cytokines, growth factors, morphogens and toll-like receptor (TLR) ligands modulates several stem cell functions [16, 34]. Here, we asked whether exposing NSCs to inflammatory cytokines, that are known to play a central role in triggering and perpetuating chronic inflammation, induces a licensing switch in their intrinsic immune regulatory functions [35].

To evaluate the effects of NSCs on acute T cell responses, we measured CD3/CD28-induced lymph node cell (LNC) proliferation by flow cytometry using a carboxyfluorescein diacetate succinimidyl ester (CFSE) dilution assay at both 48 and $72 \mathrm{~h}$ in vitro. These time points were selected based 
on previous data on proliferation and activation of rodent LNCs in vitro [36]. LNCs were also stained with anti-CD44 antibodies to detect their activation. NSCs were first primed for $16 \mathrm{~h}$ in vitro with a Th1-like cytokine cocktail composed of IFN- $\gamma$, TNF- $\alpha$ and IL-1 $\beta$ or a Th2-like cytokine cocktail composed of IL-4, IL-5 and IL-13 [33], and then tested for their immune modulatory activity in same well co-cultures with LNCs (Th1 NSC/LNC and Th2 NSC/LNC, respectively). Co-cultures of basal (e.g. not exposed to cytokines) NSCs and LNCs (NSC/LNC) or LNC preparations only (LNC) were used as controls.

By $48 \mathrm{~h}$, significantly higher proportions of $\mathrm{CD}^{+} \mathrm{T}$ cells started to proliferate (CSFE ${ }^{\mathrm{dim}}$ ) in NSC/LNC [43.7\% $( \pm 4.2)]$, Th1 NSC/LNC $[48.2 \%( \pm 1.5)]$ and Th2 NSC/LNC $[39.2 \%( \pm 1.1)]$ vs. LNC $[2.64 \%( \pm 0.18) ; p \leq 0.0001]$ (Fig. 1a, b). By $72 \mathrm{~h}$, the fraction of $\mathrm{CFSE}^{\mathrm{dim}} \mathrm{CD} 4^{+} \mathrm{T}$ cells further increased in all conditions, still being slightly more represented in NSC/LNC [83.9 \% $( \pm 0.9)]$, Th1 NSC/LNC $[86.8 \%( \pm 1.7)]$ and Th2 NSC/LNC $[87.8 \%( \pm 0.1)]$, vs. LNC [77.3\% ( \pm 2.72$) ; p \leq 0.05$ and $p \leq 0.01$ ] (Fig. 1a, b). Nevertheless, we noticed a significantly higher proportion of CFSE${ }^{\mathrm{dim}} \mathrm{CD}^{+} \mathrm{T}$ cells expressing low levels of the activation marker CD44 (CFSE $\left.{ }^{\mathrm{dim}} \mathrm{CD} 44^{\text {low }}{ }^{\mathrm{CD}} 4^{+}\right)$within $\mathrm{NSC} / \mathrm{LNC}$, Th1 NSC/LNC and Th2 NSC/LNC at both 48 and $72 \mathrm{~h}$ [ $p \leq 0.001$ vs. LNC] (Fig. 1a, c). Comparable results were obtained when NSCs were co-cultured with purified $\mathrm{CD} 4^{+}$ $\mathrm{T}$ cells for $72 \mathrm{~h}$ in vitro (Additional file 1: Figure S1), thus suggesting a direct effect of NSCs on $\mathrm{CD} 4^{+} \mathrm{T}$ cells.

Significantly higher proportions of $\mathrm{CSFE}^{\mathrm{dim}} \mathrm{CD} 44^{\text {high }}$ $\mathrm{CD}^{+}{ }^{+} \mathrm{T}$ cells were also observed by $48 \mathrm{~h}$ in NSC/LNC [36.8 \% ( \pm 3.3$)]$, Th1 NSC/LNC [39.3\% $( \pm 1.6)]$, and Th2 NSC/LNC [31.4\% $( \pm 0.8)]$ compared to LNC [1.6 \% ( \pm 0.1$)$; $p \leq 0.0001]$. By contrast, no differences in the proportion of $\mathrm{CD} 4^{+} \mathrm{CSFE}^{\mathrm{dim}} \mathrm{CD} 44^{\text {high }} \mathrm{T}$ cells were observed by $72 \mathrm{~h}$ in any of the conditions tested (Fig. 1a, d).

LNCs in co-cultures at $72 \mathrm{~h}$ also showed a higher CFSE content $\left(\mathrm{CFSE}^{\text {high }}\right)$ vs. control LNC (Fig. 1e). This CFSE ${ }^{\text {high }}$ late LNC behaviour did not account for any significant differences in the proportion of TO-PRO3 ${ }^{+}$apoptotic $\mathrm{CD} 4$ ${ }^{+} \mathrm{T}$ cells; yet, it was associated to significant $4-8$-fold higher survival of LNCs in co-cultures $[p \leq 0.01$ and $p \leq 0.001]$ vs. control LNCs (Additional file 2: Figure S2).

We therefore reasoned that these results might suggest that only in the presence of NSCs, T cells survive better and undergo transient early activation and proliferation, while prematurely exiting from the cell cycle [37]. To address this hypothesis, we analysed the ability of T cells in co-cultures to enter S-phase (synthesis phase) of the cell cycle at $72 \mathrm{~h}$ upon exposure to a 5-h-long pulse with 5-ethynyl-2'-deoxyuridine (EdU).

We found a significant $38 \%$ reduction of the fraction of $\mathrm{CD}^{+} \mathrm{T}$ cells incorporating EdU in NSC/LNC cocultures $[22.50 \%( \pm 0.4)]$ vs. control LNC [35.80\% $( \pm 2.9) ; p \leq 0.01$ ] (Fig. 2). This effect became even more striking in Th1 NSC/LNC and Th2 NSC/LNC, which showed 56-61 \% inhibition of the EdU uptake [Th1 NSC/LNC: $14.17 \%( \pm 3.3)$; Th2 NSC/LNC: $15.9 \%$ ( \pm 1.8 ); all $p \leq 0.001$ vs. controls], thus confirming that cytokine-induced NSC-reactive signals may hinder optimal cell cycle progression in target T cells [8].

Together, these data confirm the ability of NSCs to affect $\mathrm{T}$ cell activation and proliferation and suggest that cytokine signalling (priming) on NSCs provides a higher anti-proliferative effect.

\section{Untargeted metabolomic studies identifies defective arginine metabolism in Th1 NSCs}

To investigate whether the exposure to a Th1-like cytokine cocktail induced a metabolic alteration in NSCs, which could interfere with the NSCs-T cell crosstalk, we performed untargeted intracellular (endometabolome) and extracellular (exometabolome) metabolomic profiling of basal and Th1 NSCs. NSCs primed with Th2-like cytokine cocktails (Th2 NSCs) were used as additional controls. GC/MS and LC/MS in positive ion mode and negative ion mode were performed according to the different metabolite ionization properties. In total, 215 and 86 metabolites were identified for the NSCs endo and exo, when comparing basal, Th1 or Th2 NSCs. These analytes spanned many classes of metabolites, including amino acids, carbohydrates, peptides, lipids and nucleotides (Additional file 3: Table S1).

Welch's two-sample $t$ tests were used to identify exoand endo-metabolites that differed significantly between the experimental groups (Tables 1 and 2). On the one hand, we found a total of 14 and 7 exo-metabolites that were significantly upregulated in the conditioned media of Th2 NSCs and Th1 NSCs, respectively, compared to basal NSCs. On the other hand, we found a total of 2 and 1 exo-metabolites that were significantly downregulated in the conditioned media of Th2 NSCs and Th1 NSCs, respectively, compared to basal NSCs (Table 1).

When we instead analysed the endometabolome of NSCs, we found that Th1 NSCs had more pronounced alterations with respect to Th2 NSCs and basal NSCs. On the one hand, a total of 32 endo-metabolites were significantly upregulated in Th1 NSCs ( $p \leq 0.05$ vs. basal NSCs) compared to the only 9 endo-metabolites that were significantly upregulated in Th2 NSCs. On the other hand, 19 endo-metabolites were significantly downregulated in Th1 NSCs ( $p \leq 0.05$ vs. basal NSCs) compared to the only 4 endo-metabolites downregulated in Th2 NSCs (Table 2).

Most importantly, partial least squares discriminant analysis (PLS-DA) clearly segregated basal, Th1 or Th2 NSCs in separate clusters (Fig. 3a). Each condition clustered separately, thus indicating that each NSC metabolic profiles were highly specific. Out of the 215 


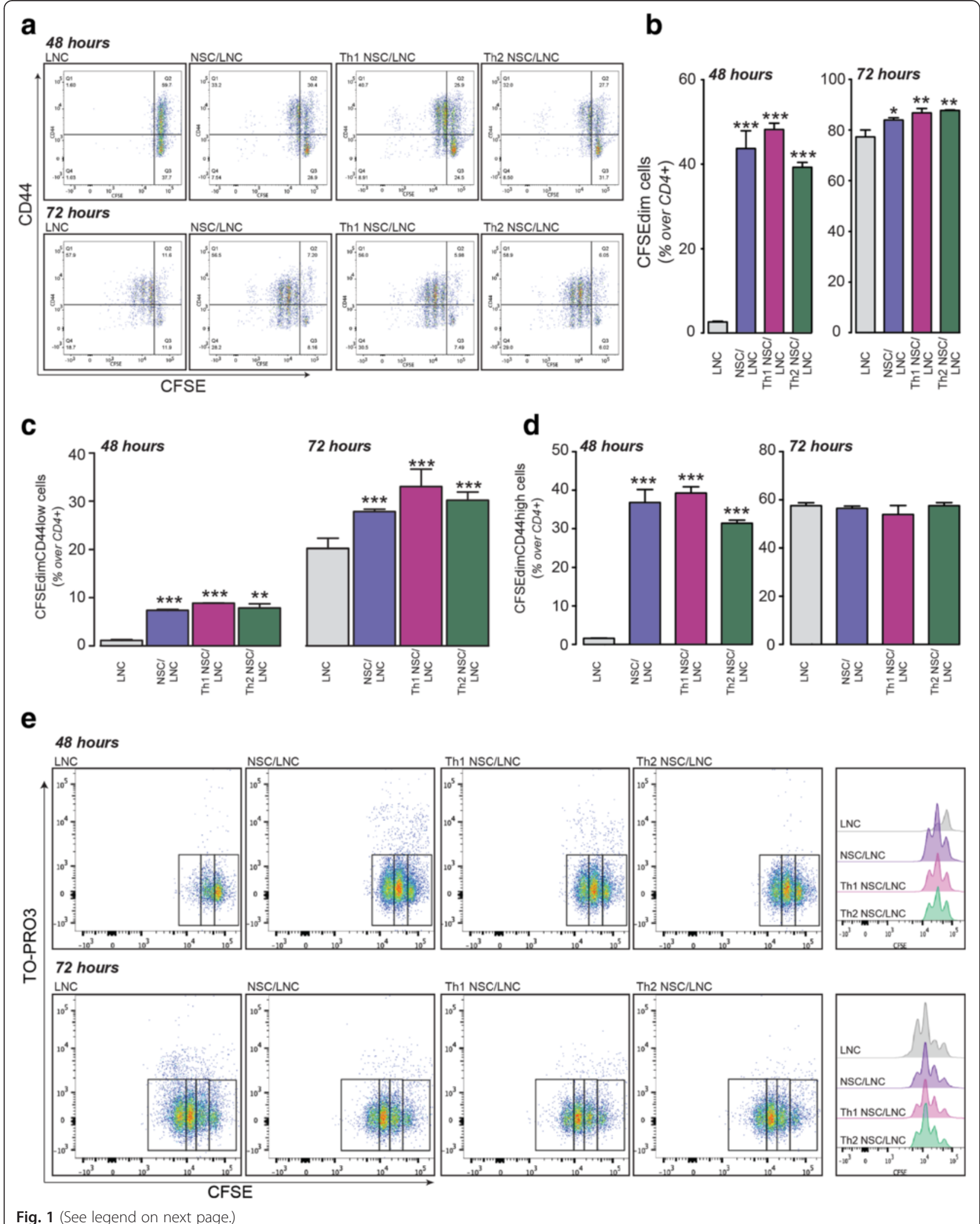

Fig. 1 (See legend on next page.) 
(See figure on previous page.)

Fig. 1 Cytokine-primed NSCs hinder lymph node cell (LNC) proliferation and cause premature CD44 downregulation. Unfractionated LNC were labelled with the vital dye CFSE, cultured on CD3/CD28 coated mAb in the absence or the presence of NSCs, Th1 NSCs, or Th2 NSCs for 48 and $72 \mathrm{~h}$ in vitro. a Cells were surface stained with anti-CD4 and CD44 antibodies. Dot plots depict relative CD44 and CFSE levels and are representative of gated $\mathrm{CD}^{+}$viable cells. b-d Absolute fractions of CFSE ${ }^{\text {dim }}$ (b), CFSE ${ }^{\text {dim }}$ CD44 ${ }^{\text {low }}$ (c), and CFSE ${ }^{\text {dim }}$ CD44 ${ }^{\text {high }}$ $\mathrm{CD}^{+} \mathrm{T}$ cells are shown (d). Data in $\mathbf{b}-\mathbf{d}$ are expressed as mean \% $( \pm \mathrm{SD})$ and have been collected out of $n \geq 3$ independent experiments. e Representative dot plots of relative CFSE and TO-PRO3 levels after gating on CD4 ${ }^{+} \mathrm{T}$ cells as in a-d. Unpaired two-tailed $t$ test for comparisons between groups were applied; ${ }^{*} p \leq 0.05 ;{ }^{* *} p \leq 0.01 ;{ }^{* * *} p \leq 0.001$ vs. LNC

identified endo-metabolites, 61 were significantly different between basal, Th1, and Th2 NSCs, as depicted in the heatmap of the hierarchical clustering of the MS peak intensities (Fig. 3b; $p \leq 0.05$ ).

We then focused on the endometabolome, to investigate the possible metabolic determinants of the enhanced immune regulatory function of Th1 NSC on T cells. To identify the intracellular metabolic pathways that were mostly altered in Th1 NSCs (vs. basal NSCs), we performed a metabolic pathway analysis (MetPA) on differentially represented metabolites by using Metaboanalyst, a web-based tool for metabolomic data interpretations [38]. This analysis identified multiple intracellular metabolic pathways as being altered in Th1 NSCs (vs. basal NSCs). Metabolites belonging to the metabolism of arginine and proline, of phenylalanine and of tyrosine and tryptophan were differentially enriched in Th1 NSCs (vs. basal NSCs) (Fig. 4). In particular, when considering

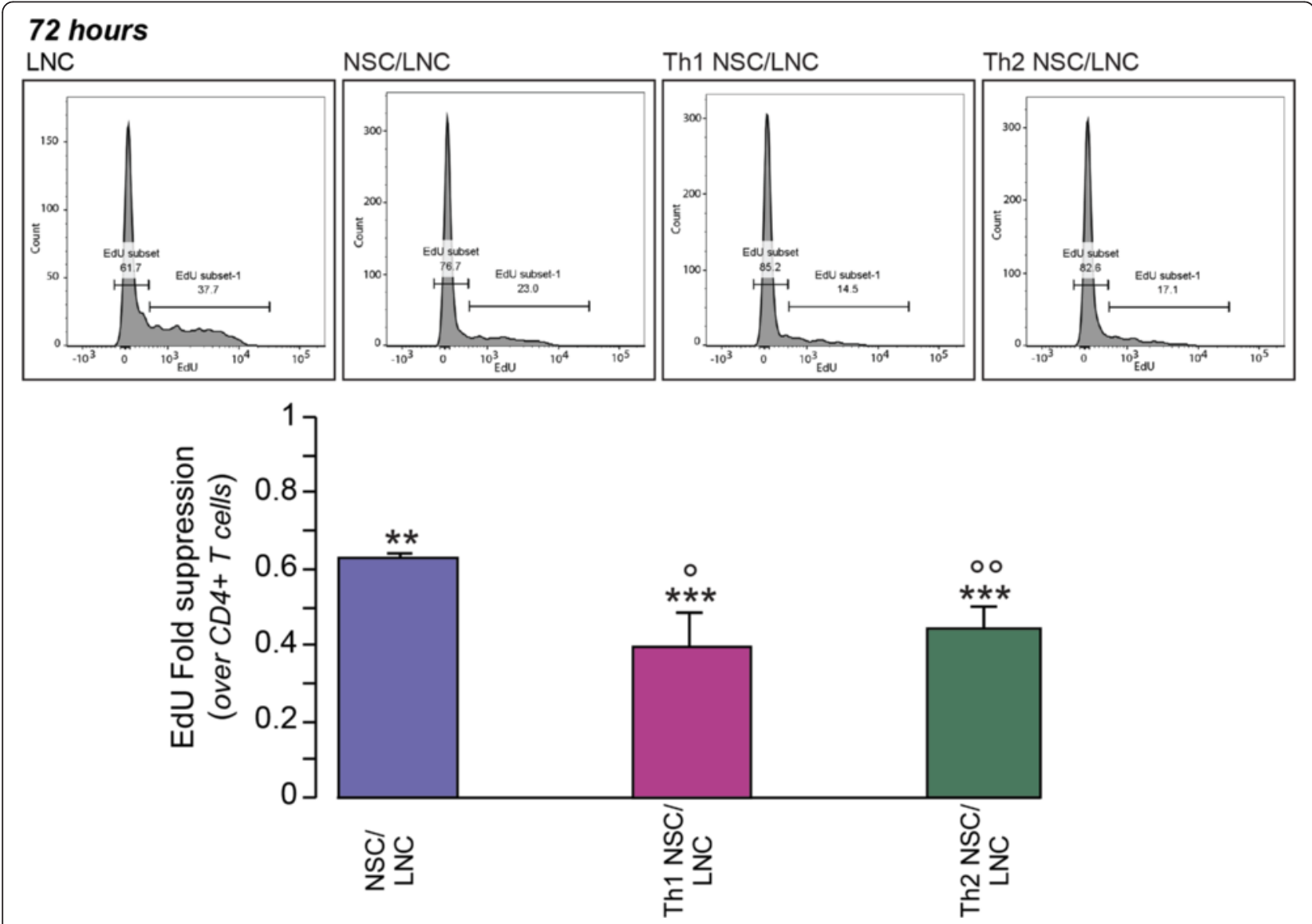

Fig. 2 Cytokine-primed NSCs hinder cell cycle progression in LNC in vitro. Unfractionated LNC were co-cultured with NSC for $72 \mathrm{~h}$ as in Fig. 1. EdU was added to the cells for the last $5 \mathrm{~h}$ of culture. Cells were then recovered, labelled with anti-CD4 mAb, stained for intracellular EdU content, and analysed by flow cytometry. Events are depicted after gating on $C D 4^{+} \mathrm{T}$ cells. Relative fractions of EdU ${ }^{+}$cells are represented. Data are expressed as mean EdU fold suppression $\left( \pm S D\right.$ ) calculated by dividing the percent of EdU ${ }^{+} C D 44^{\text {high }}$ cells over the control CD4 ${ }^{+} T$ cells from $n \geq 3$ independent experiments. Unpaired two-tailed $t$ test for comparisons between groups were applied; ${ }^{* *} p \leq 0.01$ and ${ }^{* *} p \leq 0.001$ vs. LNC; ${ }^{\circ}$ $p \leq 0.05$ and ${ }^{\circ} p \leq 0.01$ vs. NSCs/LNC 
Table 1 Summary table for untargeted endo and exo-metabolomic NSC profiling: NSC exometabolome

\begin{tabular}{l|c|c|c}
\hline Welch's two sample $t$-test_NSC exometabolome & Th1 NSCs/basal NSCs & Th2 NSCs/basal NSCs & Th1 NSCs/Th2 NSCs \\
\hline Total number of biochemicals with $p \leq 0.05$ & 8 & 16 & 10 \\
\hline Biochemicals $(\uparrow \downarrow)$ & $7 / 1$ & $14 / 2$ & $1 / 9$ \\
\hline Total number of biochemicals with $0.05<p<0.10$ & 6 & 10 & 7 \\
\hline Biochemicals $(\uparrow \downarrow)$ & $3 / 3$ & $8 / 2$ & $2 / 5$ \\
\hline
\end{tabular}

Welch's two-sample $t$ tests were used to identify metabolites that are significantly regulated between experimental groups within cells (Table 1) or in the media (Table 2) (up regulated metabolites are in red whereas downregulated metabolites are in green)

the $\log p$ value, differences in the arginine and proline metabolism of Th1 NSCs were the most significant when compared to basal NSCs (Additional file 4: Table S2). Accordingly, the arginine downstream metabolites agmatine, $\mathrm{N}$-acetylputrescine and 4-guanidinobutanoate-which are all members of the arginine decarboxylase pathway-were significantly upregulated in Th1 NSCs $(p \leq 0.01$ and $p \leq$ 0.05 vs. basal and Th2 NSCs) (Fig. 5).

Untargeted metabolomics can therefore be efficiently used to identify several differences in the endo- and exometabolome of primed NSCs. In particular, we found that arginine and proline are the most differentially regulated in the endometabolome of Th1 NSCs.

\section{Targeted metabolomics identifies defective arginase activity within the urea cycle in Th1 NSCs}

Arginine levels have been reported to be critical for $\mathrm{T}$ cell activation and proliferation [39]. Therefore, we decided to focus on the intracellular arginine metabolism to clarify which metabolic routes were specifically altered in Th1 NSCs. The cells were incubated with uniformly labelled $\mathrm{U}^{13} \mathrm{C}_{6} \mathrm{~L}$-arginine in the absence or in the presence of Th1 and Th2 cytokines and isotopologues distribution of arginine and downstream metabolites was assessed by LC/ MS (Fig. 6). Within $2 \mathrm{~h}$, the amount of labelled intracellular arginine $(m+6)$ was significantly lower in Th1 NSCs $(p \leq 0.01)$, when compared to both basal and Th2 NSCs (Fig. 6a). In addition, labelled ornithine $(m+5)$ was undetectable in Th1 NSCs by $2 \mathrm{~h}$ (Fig. $6 \mathrm{~b}$ ), and overall levels of unlabelled ornithine $(\mathrm{m}+0)$ were lower in these cells $(p \leq 0.05)$. By $16 \mathrm{~h}$, differences in the arginine and ornithine intracellular levels between basal NSCs and Th1 NSCs were no longer statistically significant.

The reduced amount of $m+6$ arginine (Fig. 6a) and $m+5$ ornithine (Fig. $6 \mathrm{~b}$ ), together with lower unlabelled $\mathrm{m}+0$ intracellular ornithine, supported a deregulation of arginine metabolism within the urea cycle in Th1 NSCs (Fig. 6e). Since arginase is the urea cycle enzyme involved in the conversion of arginine to ornithine and urea (Fig. 6e), we hypothesized that the observed metabolic changes were depending on the defects of arginase activity. To verify this hypothesis, we measured the arginase enzymatic activity in cell extracts and assessed urea production by a colorimetric assay. Th1 NSCs showed a significant decrease in the arginase activity (Fig. 6c) and in the rate of urea production, compared to basal and Th2 NSCs $(p \leq 0.05$ and $p \leq 0.01)$ (Fig. 6d).

Altogether, these findings suggest that inflammatory cytokine signalling causes a selective defect of arginase activity in Th1 NSCs.

\section{Expression of different arginase isoforms in NSCs}

To further understand the regulation of arginase in cytokine-primed NSCs, we first investigated the expression of inducible (type I) and constitutive (type II) arginases in NSCs in vitro. We used immunofluorescence staining of Mito-DsRed-transduced Nestin ${ }^{+}$NSCs to quantify the subcellular localization of cytosolic (type I) and mitochondrial (type II) arginase isoforms. We observed low basal expression of both arginases in NSCs and found that NSCs primed with Th1 cytokines had a significantly downregulated expression of arginase II, coupled with a significantly increased expression of arginase I (Fig. 7a).

As confirmation of these in vitro data, we interrogated a more physiological inflammatory context to examine the expression of both arginases by NSCs in vivo within brain germinal niches [40]. In mice with myelin oligodendrocyte glycoprotein (MOG)-induced experimental autoimmune encephalomyelitis (EAE), as model of Th1like antigen-specific chronic inflammatory disease of the central nervous system [41], we found a downregulation of arginase II and concomitant upregulation of arginase I in

Table 2 Summary table for untargeted endo and exo-metabolomic NSC profiling: NSC endometabolome

\begin{tabular}{l|c|c|c}
\hline Welch's two sample $t$-test NSC endometabolome & Th1 NSCs/basal NSCs & Th2 NSCs/basal NSCs & Th1 NSCs/Th2 NSCs \\
\hline Total number of biochemicals with $p \leq 0.05$ & 51 & 13 & 23 \\
\hline Biochemicals $(\uparrow \downarrow)$ & $32 / 19$ & $9 / 4$ & $8 / 15$ \\
\hline Total number of biochemicals with $0.05<p<0.10$ & 29 & 14 & 28 \\
\hline Biochemicals $(\uparrow \downarrow)$ & $20 / 9$ & $8 / 6$ & $16 / 12$ \\
\hline
\end{tabular}

Welch's two-sample $t$ tests were used to identify metabolites that are significantly regulated between experimental groups within cells (Table 1) or in the media (Table 2) (upregulated metabolites are in red whereas downregulated metabolites are in green) 
a Scores Plot

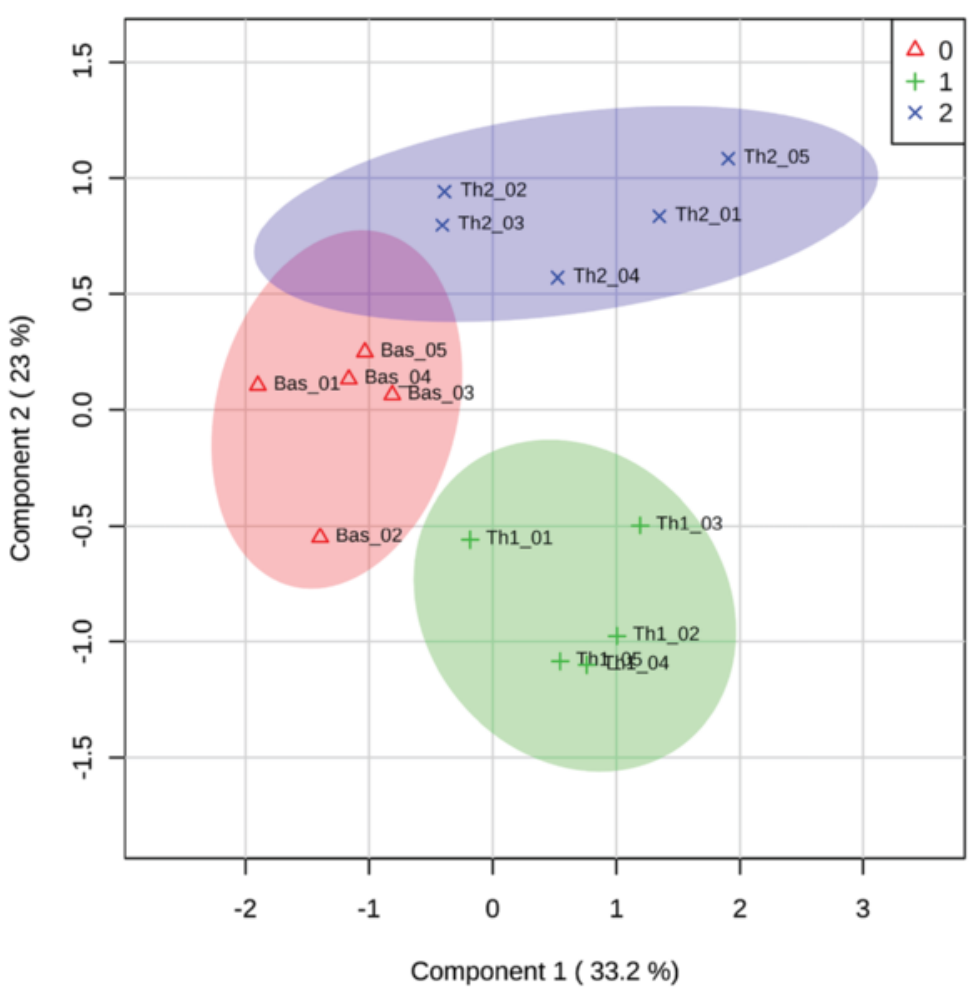

b
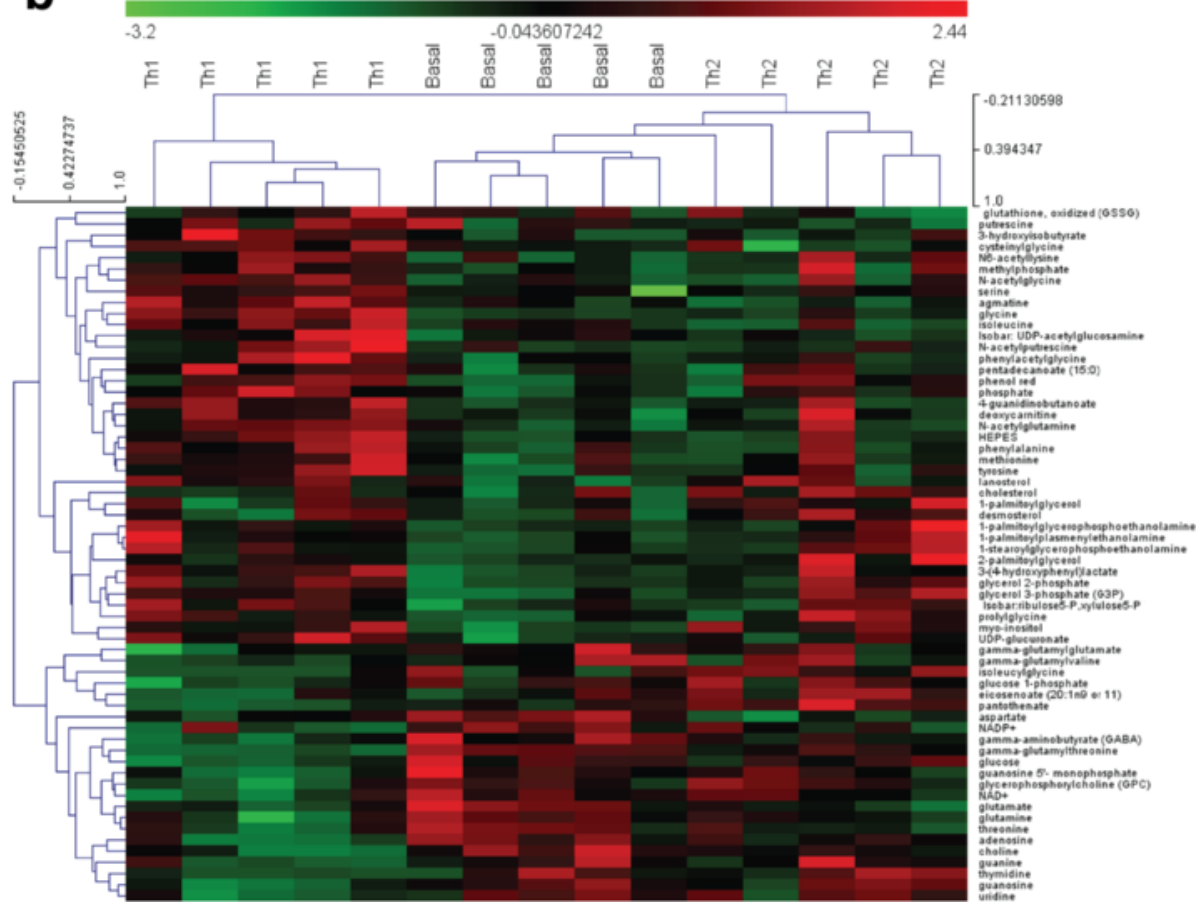

Fig. 3 (See legend on next page.) 
(See figure on previous page.)

Fig. 3 Untargeted metabolomics analysis of NSCs under Th1- and Th2-like cytokines: Multivariate analysis (PLS-DA) and hierarchical clustering. a PLS-DA score assessing the clustering of the three sample groups (basal NSCs (group 0), Th1 NSCs (group 1), or Th2 NSCs (group 2)) was performed on significant metabolites by using MetaboAnalyst 2.0 software. $\mathbf{b}$ Hierarchical clustering heatmap for MS peak intensities of significantly $(p \leq 0.05)$ different intracellular metabolites among basal NSCs, Th1 NSCs, or Th2 NSCs. MultiExperiment Viewer software (MeV) (v 4.6.2) was applied on NSCs significant endometabolome dataset with Pearson correlation metric. Sixty-one intracellular metabolites were significantly different in the three experimental conditions among 215 identified metabolites by LC-MS/MS and GC-MS/MS

Nestin $^{+}$NSCs of the SVZ at both 25 and 50 days after immunization vs. healthy controls (Fig. 7b).

These findings suggest that the previously observed decrease in the intracellular arginase activity in Th1 NSCs might well be ascribed to an imbalance between decreased arginase II expression (e.g. controlled at the post-translational level) and increased arginase I.

We then reasoned that (i) a shift in arginine metabolism and (ii) subsequent secretion of active arginases might be driving some of the immune modulatory properties of cytokine-primed NSCs.

To address the latter of these outstanding questions, we performed western blot analysis for both arginase I and II in NSC-conditioned media and found evidence of secreted arginase I, but not of arginase II (Fig. 7c). The secretion of arginase I might be an active secretion process by NSCs, instead of being a bystander effect of
NSC death, as suggested by the comparable viability of basal, Th1 and Th2 NSCs (Additional file 5: Figure S3).

\section{Extracellular arginase I drives NSC modulation of T cell responses}

To address the role of extracellular arginases in the immune modulatory effects of Th1 NSCs, we co-cultured basal, Th1, and Th2 NSCs with LNCs in the absence or in the presence of the potent, reversible, pan-arginase inhibitor $\mathrm{N}^{\omega}$-hydroxy-nor-arginine (nor-NOHA) and measured EdU incorporation after $72 \mathrm{~h}$ in vitro.

Co-cultures with NSCs induced significant $40 \%$ reduction of the fraction of $\mathrm{CD} 44^{\text {high }} \mathrm{EdU}^{+} \mathrm{CD} 4^{+} \mathrm{T}$ cells vs. LNCs $(p \leq 0.01)$. This effect was more striking in co-cultures with Th1 and Th2 NSCs, respectively (58 and $52 \%$ reduction; $p \leq 0.01$ or $p \leq 0.05$ vs. NSC/LNC and $p \leq 0.001$ vs. LNC). Pan-arginase inhibition by nor-NOHA had no effects on

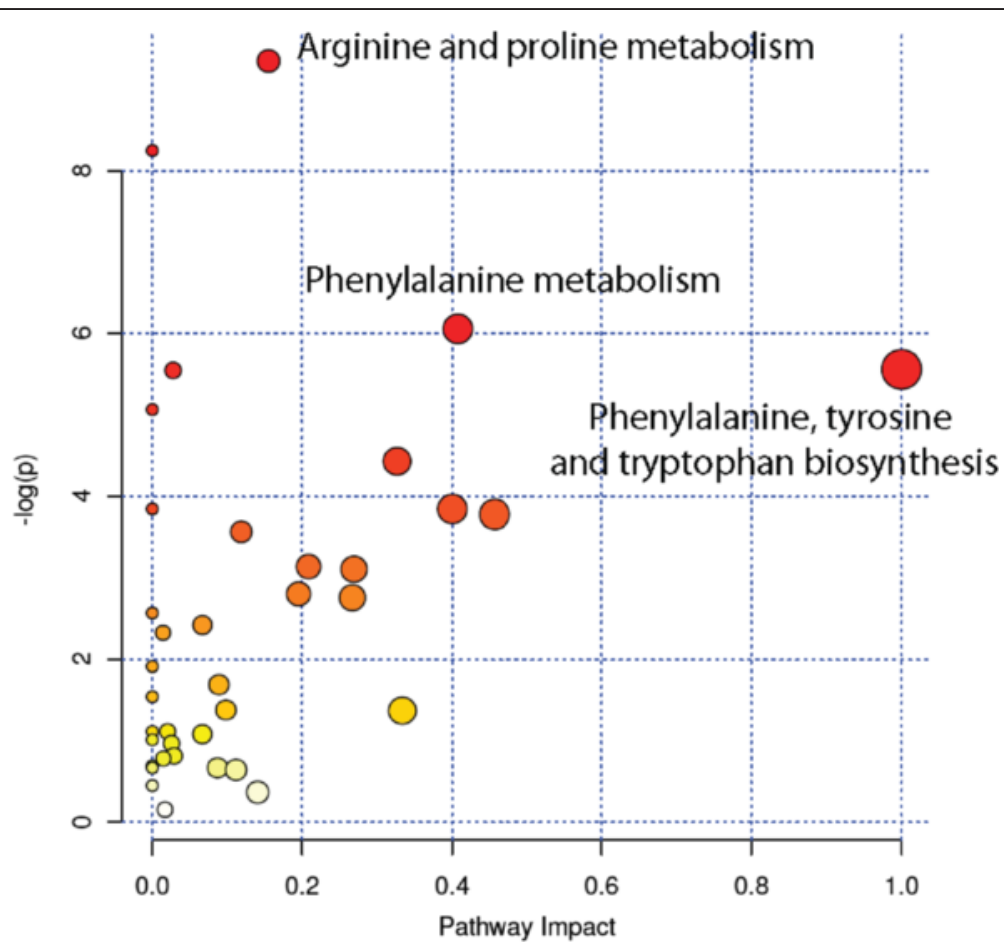

Fig. 4 Metabolic pathways analysis of Th1 NSCs. Enriched metabolic pathways were ranked according to their FDR values calculated by the MetPa method implemented in MetaboAnalyst 2.0 software. The most significant pathways for Th1 NSCs compared to basal NSCs were represented by both the bigger/red dots and by those dots with higher $\log p$ value. The pathway impact is calculated as the sum of the importance measures of the matched metabolites normalized by the sum of the importance measures of all metabolites in each pathway 

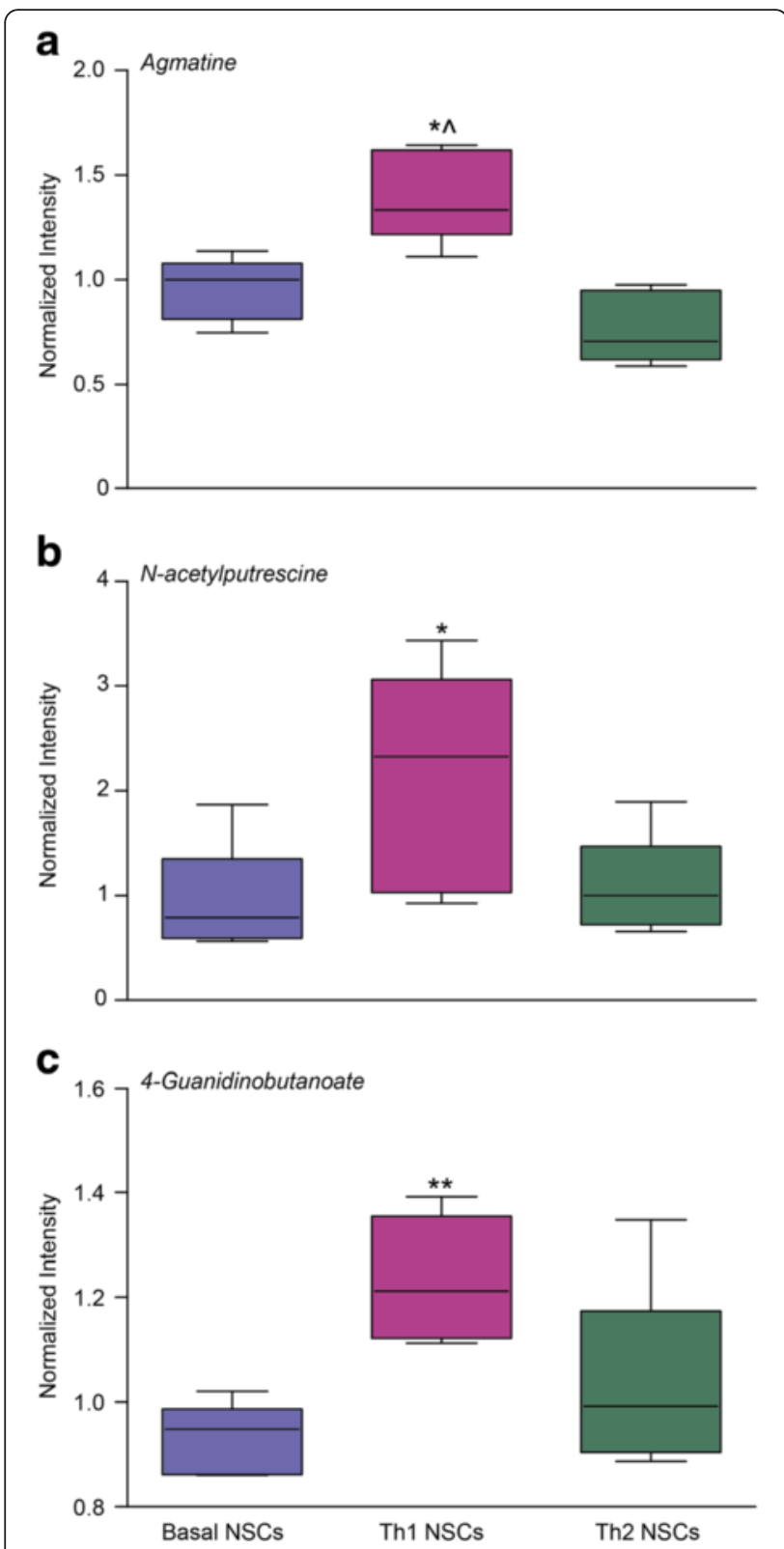

Fig. 5 Th1-like cytokines affect NSC arginine metabolism altering the levels of arginine-derived polyamines. Box plot of NSCs endo-metabolites for the arginine pathway detected by LC-MS/MS expressed as mean of MS peak intensity for five independent experiments. Agmatine (a), $\mathrm{N}$-acetylputrescine (b), and 4-guanidinobutanoate (c) levels were upregulated in Th1 NSCs compared to basal NSCs. Unpaired two-tailed $t$ test for comparisons between groups were applied. ${ }^{*} p \leq 0.05$ and ${ }^{* *} p \leq 0.01$ vs. basal NSCs, $\wedge p \leq 0.05$ vs. Th2 NSCs

NSC/LNC but induced a $13 \%$ rescue of the antiproliferative properties of Th1 NSCs $(p \leq 0.01$ vs. NSC/ $\mathrm{LNC}+$ nor-NOHA) and a further 1.8-fold lower rescue of the anti-proliferative effects in Th2 NSC/LNC ( $p \leq 0.05$ vs. Th1 NSC/LNC + nor-NOHA) (Fig. 7d, e).

The fact that cytokine-primed NSCs were still in part capable to inhibit $\mathrm{T}$ cells proliferation in the presence of pan-arginase inhibition suggests that mechanisms other than extracellular arginase I or II contribute to the broad NSCs immune regulatory activities, as described elsewhere [3].

Overall, our findings suggest that deregulation of the arginine pathway and the release of arginase I contribute to part of the NSCs immune regulatory activities, especially in the case of NSCs primed with extracellular inflammatory signals.

\section{Discussion}

Recent studies revealed that NSCs secrete neuroprotective and immune regulatory molecules able to mediate a cross talk with the surrounding tissues after transplantation and provide significant modulation of immune responses both in vitro and in vivo $[16,42]$. While no final mechanisms or direct evidence of stem cell-to-immune system interaction is yet available, a number of studies are now focussing on the cellular signalling between grafted stem cells and endogenous target cells, with the aim of clarifying its physiological or circumstantial nature, and elucidating its molecular signature and therapeutic potential $[15,43,44]$. Whether and how cytokines produced in the CNS inflammatory or ischaemic environment in vivo modulate the NSCs immune regulatory activity is not unravelled yet but represents an intriguing possibility in developing more effective NSC-based therapeutic approaches [16]. Therefore, we reasoned that combined metabolomics-metabolic flux studies could provide useful insights into the NSC-immune cells crosstalk [45] elucidating the role of cytokines stimulation in the NSC metabolic reprogramming.

Previous evidence revealed that preconditioning (priming) of human NSCs by pro-inflammatory cytokines increased their cytotoxic activity towards human monocytic and lymphocytic cell lines via a TNF- $\alpha$-mediated mechanism [14]. Here, we confirmed the existence of a crosstalk between NSCs and LNC/T cells, which is suggested by a premature downregulation of the activation marker CD44 on $\mathrm{T}$ cells and the failure of LNC to progress through the cell cycle and to proliferate. We also found that exposing NSCs to inflammatory Th1-like or Th2-like cytokines augmented the innate NSCs ability to repress T cells proliferation.

In the attempt to find a metabolic hypothesis for the reduced $\mathrm{T}$ cell proliferation promoted by Th1 or Th2 NSCs, we performed untargeted metabolomics by LC-MS/MS and GC-MS/MS, which covered a wide panel of both intracellular and extracellular metabolites belonging to the most important biochemical pathways. By high-throughput metabolomics, we found an alteration of intracellular arginine metabolism in NSCs, which was especially evident in Th1 NSCs and well correlated with the NSC antiproliferative effect on T cells. We observed that the metabolism of arginine and proline was the most significant 


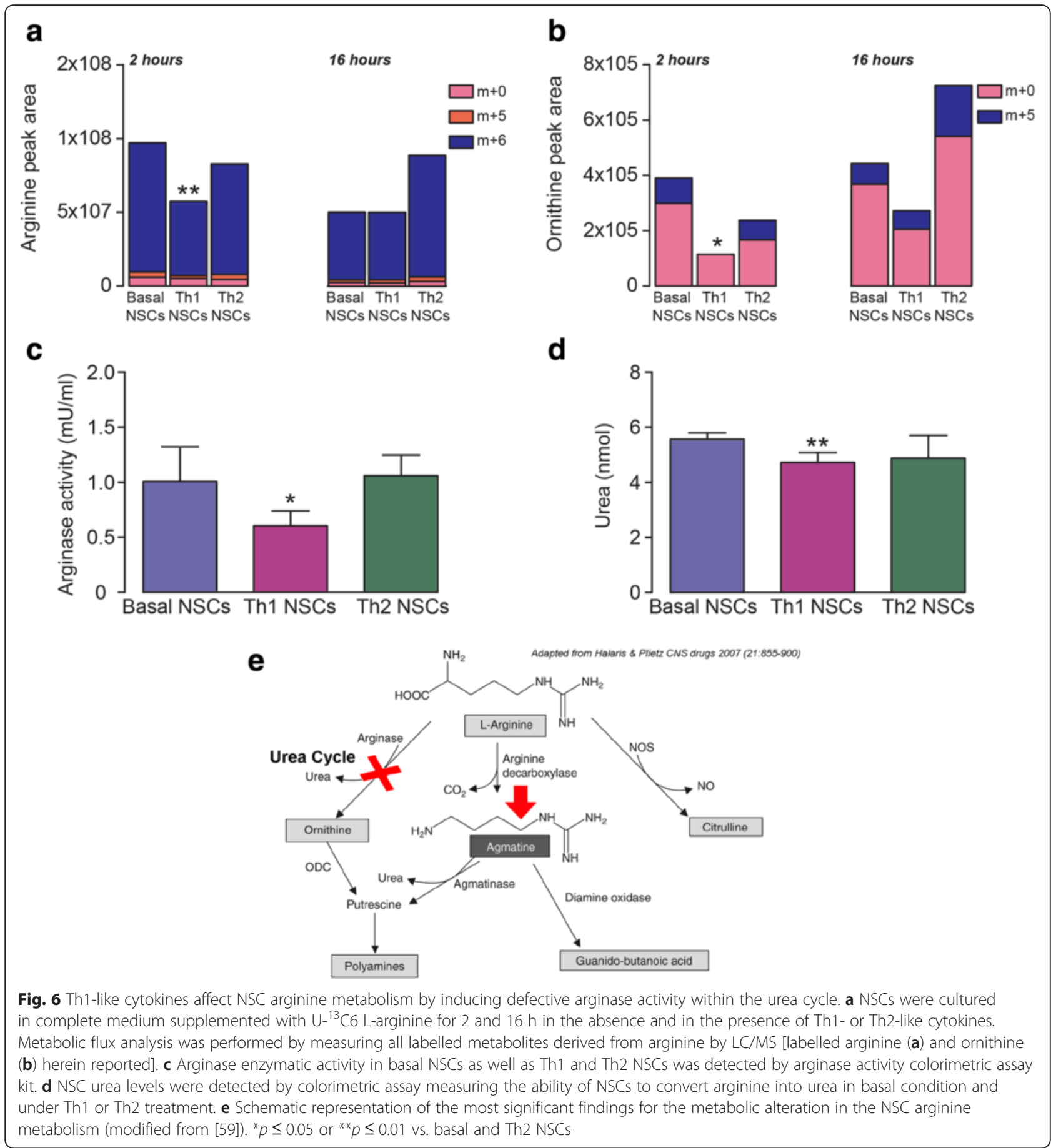

altered pathway for Th1 NSCs. This was supported by a significant decrease of arginase enzymatic activity and urea production as well as by the upregulation of other intracellular downstream arginine metabolites such as agmatine, $\mathrm{N}$-acetylputrescine and 4-guanidinobutanoate.

Relative metabolite concentration changes are not sufficient to infer directionality of metabolic rates (fluxes) [46]. Thus, to investigate and validate changes in arginine metabolism, we incubated cells with $\mathrm{U}_{-}{ }^{13} \mathrm{C}_{6} \mathrm{~L}$ - arginine. This analysis confirmed the arginine pathway as the most relevant biochemical system affected by Th1-like (but not Th2-like) cytokines. The upregulation of arginine downstream metabolites such as agmatine, $\mathrm{N}$-acetylputrescine and 4-guanidinobutanoate shown by untargeted metabolomics might mirror the significantly decreased amount of intracellular arginine-as such being predictive of faster arginine turnover-in Th1 NSCs. Changes in intracellular metabolic fluxes were best 


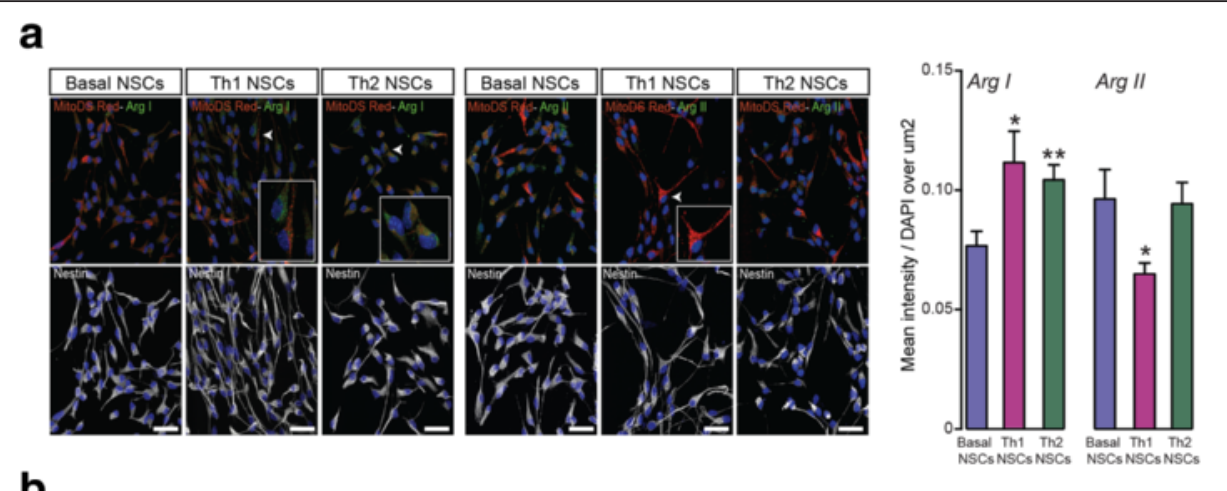

b

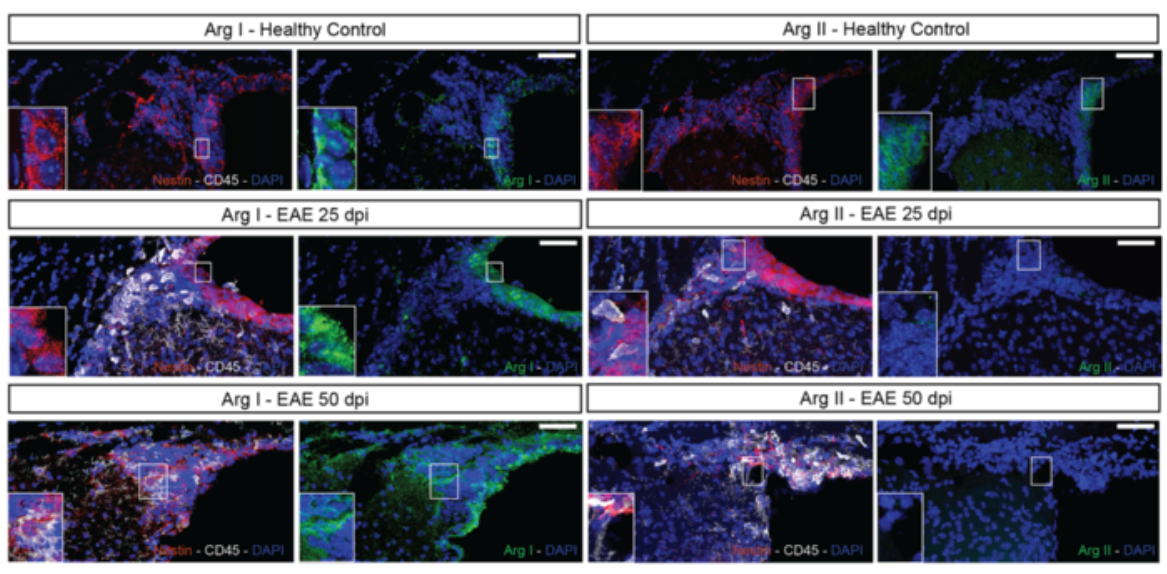

C

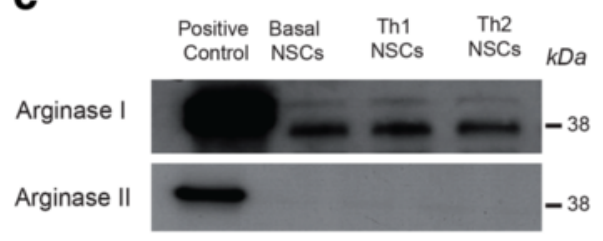

d

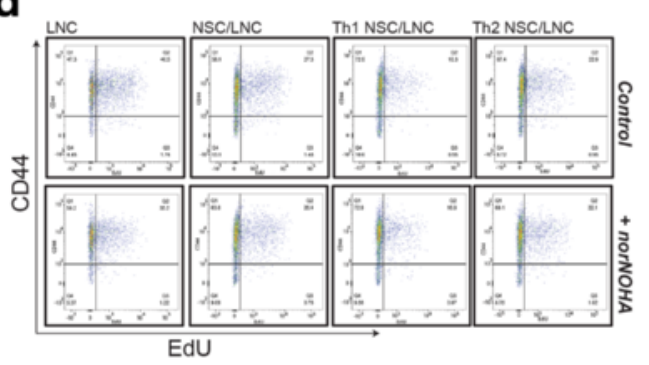

e

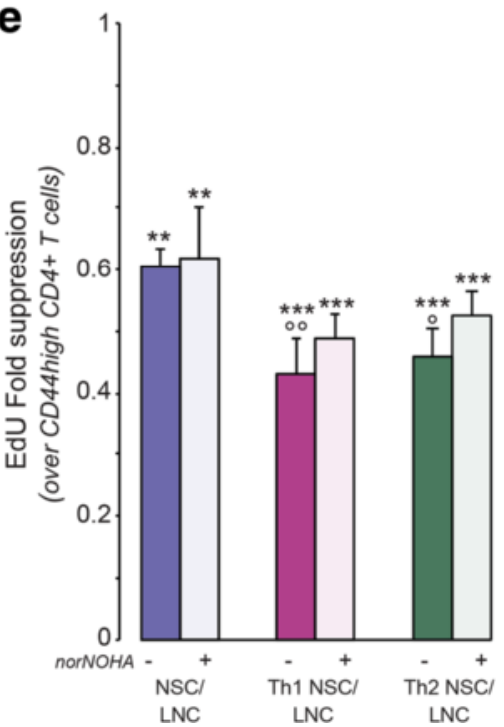

Fig. 7 (See legend on next page.) 


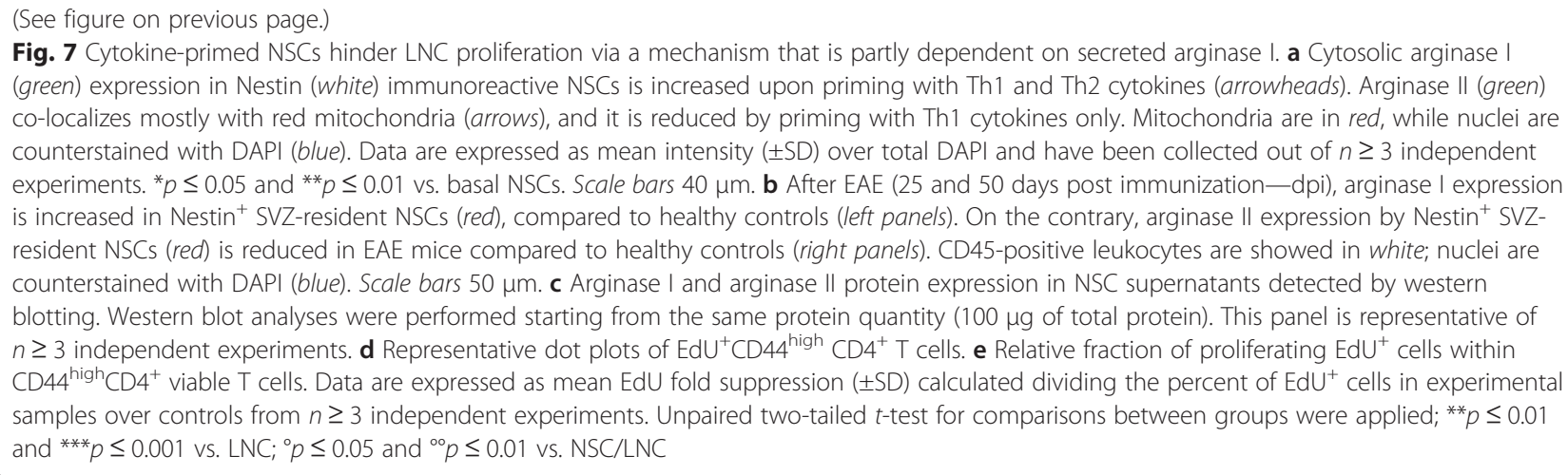

detected within $2 \mathrm{~h}$ of cytokine stimulation, while NSC inhibitory activities in NSCs/T cell co-cultures were observed at later times $(48-72 \mathrm{~h})$. We speculate the former changes to occur early after cytokine stimulation, while the latter ones to be better observed at later times as possibly caused by transcriptional or translational events controlled by changes in NPCs metabolic fluxes.

Arginase catalyzes the conversion of arginine to ornithine and urea [47]. While arginase II is constitutively expressed as the principal isoform in the nervous system and is localized in the mitochondria [48], arginase I is normally not expressed but induced in the cytosol. Arginase I expression in myeloid-derived suppressor cells (MDSCs) mediated their immunosuppressive activity in cancer patients [49] by depleting arginine in the tumour microenvironment and subsequently inhibiting $\mathrm{T}$ cell proliferation [49-51]. Arginase I secretion by mature myeloid cells in the tumour microenvironment inhibits antigen-specific $\mathrm{T}$ cell responses [52]. Likewise, overexpression of the extracellular arginase I contribute to the anti-inflammatory phenotype of phosphatase and tensin homolog (PTEN)-deficient myeloid cells [53].

We found that in vitro NSCs constitutively express arginase I, upregulate its expression upon priming with Th1 or Th2 cytokines and secrete it in tissue culture media. This is not surprising, as arginase I is not highly expressed in the healthy CNS $[40,54]$, but it is instead significantly upregulated in inflammatory conditions. As a matter of fact, sustained enhancement of arginase I expression has been well described during EAE within the spinal cord of both mice and rats [55]. However, this increase has been related so far to the prevailing M2 phenotype of local mononuclear phagocytes rather than being intrinsic to the CNS parenchyma [56]. Our findings suggest that arginase I is indeed upregulated in Nestin ${ }^{+}$ NSCs of the SVZ at both 25 and 50 dpi in EAE mice.

We also found that in vitro NSCs constitutively express arginase II and its expression is reduced by Th1 cytokines in vitro (while Th2 cytokines have no effect). Accordingly, in our in vivo settings, we found that arginase II is downregulated in the SVZ of EAE mice at chronic time points (i.e. 25 and $50 \mathrm{dpi}$ ). This is in line with previous data showing that arginase II gene expression rises in the spinal cord of EAE mice at the peak of disease, but it soon falls to levels below the baseline during recovery [57].

To understand whether changes in arginase activity in NSCs could be involved in their immune modulatory properties, we treated NSCs with the pan-arginase inhibitor nor-NOHA. We found that nor-NOHA had no effects on NSC/T cells but induced significant rescue of the antiproliferative effects especially for Th1 NSCs in co-cultures with $\mathrm{T}$ cells in vitro. In the presence of nor-NOHA, Th1 NSCs-and to a 1.8-fold lower extent Th2 NSCs-no longer differed from control NSCs, thus suggesting that arginase inhibition partially rescues the anti-proliferative effects of NSCs. As arginase I-but not arginase II-was mainly present in the extracellular compartment, we speculated that nor-NOHA could mostly inhibit extracellular arginase I function in NSC/LNC co-cultures.

However, we cannot exclude that this pan-arginase inhibitor could also have an effect on the intracellular arginase II and therefore the observed rescue of the antiproliferative activity observed for both Th1 and Th2 NSC/LNC may well be the sum of both the effects of the arginase inhibitor on intracellular arginase II and extracellular arginase I, as described [58].

We therefore hypothesized that defective intracellular arginase activity in cytokine-primed NSCs induces a rearrangement of intracellular arginine pool and that this effect together with the secretion of arginase I might reduce the pool of extracellular arginine, needed for proper $\mathrm{T}$ cell expansion.

Consistent with this hypothesis, we showed that the arginase I NSCs secretion could be partly responsible for the immune suppressive effects especially when NSCs sense the inflammatory environment (e.g., via cytokine receptors) [15].

The finding that nor-NOHA only partially rescued the anti-proliferative activity of cytokine-primed NSCs suggests that targeting the arginase activity in NSCs 
could provide a new way of interfering with NSCs function in vivo and that mechanisms other than extracellular arginase I would contribute to the broad NSCs immune regulatory activities [3].

\section{Conclusions}

In conclusion, our work validates the use of metabolic profiling as a hypothesis-generating tool to unravel how stem cell-mediated mechanisms of tissue restoration are affected by local inflammatory responses and identifies arginase signalling as novel mechanism of adaptive NSCto-immune system communication. While further studies are required to establish the absolute relevance of the NSC arginase-dependent immune modulatory mechanism, targeting arginase activity in NSCs could provide a new way of enhancing therapeutic immune-regulation.

Besides guiding our hypothesis on NSC immuneregulation on arginine pathway, this metabolomics approach offers a more broad and global profiling of NSCs under cytokines stimulation with other interesting pathways affected by Th1 pro-inflammatory cytokines that include phenylalanine, tyrosine and tryptophan metabolism, which are still under intense investigation. The very same technology might also be useful to investigate whether the crosstalk between NSCs and T cells occurs in a bidirectional way and if T cells alter the NSCs secretome.

Finally, we foresee that this high-throughput omic approach applied to the study of the NSCs phenotype might also provide promising therapeutic perspectives for inflammatory diseases where metabolic rearrangement plays a key role in disease progression.

\section{Additional files}

Additional file 1: Figure S1. NSCS induce downregulation of the activation cell surface marker $C D 44$ on purified $C D 4^{+} T$ cells. $C D 4^{+} T$ cells were purified by negative selection from total LNC, labelled with the vital dye CFSE, and cultured on CD3/CD28 coated mAb in the absence or the presence of NSCs, Th1 NSCs or Th2 NSCs for $72 \mathrm{~h}$. Cells were surface stained with anti-CD4 and CD44 antibodies. Absolute fractions of CFSE ${ }^{\text {dim }} C D 44^{\text {low }}$ $\mathrm{CD}^{+} \mathrm{T}$ cells are depicted. Data are expressed as mean \% ( \pm SD) from $n \geq 3$ independent experiments. ${ }^{*} p \leq 0.05$ and ${ }^{* *} p \leq 0.01$ vs. T cells.

Additional file 2: Figure S2. NSCs reduce LNC death in NSC/LNC co-cultures. LNC were labelled with the vital dye CFSE, cultured on CD3/CD28 coated mAb in the absence or the presence of NSCs, Th1 NSCs or Th2 NSCs for $72 \mathrm{~h}$. Cells were surface stained with anti-CD4, and TO-PRO3 lodide was added before flow cytometry analysis to identify dead cells. Data represent absolute fractions of TO-PRO3 ${ }^{+} \mathrm{CD}^{+}$cells and are expressed as mean \% ( $\pm \mathrm{SD}$ ) from $n \geq 3$ independent experiments. ${ }^{* *} p \leq 0.01$ and ${ }^{* * *} p \leq 0.001$ vs. LNC.

Additional file 3: Table S1. NSC endometabolome (a) and exometabolome (b) detected by LC-MS/MS or GC-MS/MS. The endometabolome and exometabolome dataset comprise a total of 215 and 86 metabolites, respectively. Following log transformation and imputation with minimum observed values for each compound, Welch's two-sample $t$ tests were used to identify metabolites that differed significantly between experimental groups. A summary of the numbers of metabolites that achieved statistical significance $(p \leq 0.05)$, as well as those approaching significance $(0.05 \leq p \leq 0.1)$, is reported. An estimate of the false discovery rate ( $q$ value) is calculated to take into account the multiple comparisons that normally occur in metabolomic-based studies.

Additional file 4: Table S2. Metabolic pathways analysis of Th1 NSCS. This table is representative of the most significant pathways for Th1 NSCs compared to basal NSCs matched according to $p$ values from pathway enrichment analysis and pathway impact values reported in Fig. 4.

Additional file 5: Figure S3. Co-culturing with LNC and cytokine priming has no effects on NSC survival. LNC were labelled with the vital dye CFSE and co-cultured with NSC, Th1 NSCs or Th2 NSCs for $72 \mathrm{~h}$ as in Additional file 2: Fig. S2. Absolute fractions of CFSE ${ }^{-} \mathrm{TO}^{\mathrm{PRO}}{ }^{+} \mathrm{CD}^{-}$cells, as an indicator of dead NSCs are expressed as mean \% ( \pm SD) from $n \geq 3$ independent experiments.

\section{Acknowledgements}

The authors acknowledge the technical help of Joshua Bernstock with the generation of the 3rd generation Mito-DsRed lentiviral vectors and Giovanni Pluchino and Lucia Zanotti for critically discussing the article.

\section{Funding}

This work has received support from the National Multiple Sclerosis Society (NMSS, partial grants RG-4001-A1), the Italian Multiple Sclerosis Association (AISM, grant 2010/R/31 and grant 2014/PMS/4), the Italian Ministry of Health (GR08-7), the European Research Council (ERC) under the ERC-2010-StG Grant agreement $n^{\circ}$ 260511-SEM_SEM and the UK Regenerative Medicine Platform Acellular hub (Partnership award RG69889) and core support grant from the Wellcome Trust and MRC to the Wellcome Trust-Medical Research Council Cambridge Stem Cell Institute. LPJ was supported by a Wellcome Trust Research Training Fellowship (RG79423).

\section{Availability of data and materials}

The datasets supporting the conclusions of this article are included within the article and its additional file(s).

\section{Authors' contributions}

$\mathrm{SP}, \mathrm{DD}$ and CF conceived the study and planned and designed the experiments, as well as wrote the manuscript. DD, VB, EG, GV and LPJ were involved in the experimental work. DD, AB, AM, GM, SP, LPJ, AA and CF analysed and interpreted the results. SP supervised the project and provided the financial support. DD, SP, CF, and AM wrote the manuscript. All authors read and approved the final manuscript.

\section{Competing interests}

The authors declare that they have no competing interests.

\section{Consent for publication}

Not applicable.

\section{Ethics approval and consent to participate}

Not applicable.

\section{Author details}

${ }^{1}$ CNS Repair Unit, Institute of Experimental Neurology (INSPE), Division of Neurosciences, San Raffaele Scientific Institute, 20132 Milan, Italy. ${ }^{2}$ Lymphocyte Activation Unit, San Raffaele Scientific Institute, 20132 Milan, Italy. ${ }^{3}$ Medical Research Council Cancer Unit, Hutchison/MRC Research Centre, Cambridge CB2 OXZ, UK. ${ }^{4}$ Biomolecular Mass Spectrometry Unit, Division of Genetics and Cell Biology, San Raffaele Scientific Institute, 20132 Milan, Italy. ${ }^{5}$ Biomolecular NMR Unit, San Raffaele Scientific Institute, 20132 Milan, Italy. ${ }^{6}$ ProMiFa, Protein Microsequencing Facility, San Raffaele Scientific Institute, 20132 Milan, Italy. ${ }^{7}$ Department of Clinical Neurosciences, Wellcome Trust-Medical Research Council Stem Cell Institute and National Institute for Health Research Biomedical Research Centre, University of Cambridge, Hills Road, CB2 OHA Cambridge, UK.

Received: 17 April 2016 Accepted: 20 July 2016 Published online: 02 September 2016 


\section{References}

1. Giusto E, Donega M, Cossetti C, Pluchino S. Neuro-immune interactions of neural stem cell transplants: from animal disease models to human trials. Exp Neurol. 2014;260:19-32.

2. Martino G, Pluchino S, Bonfanti L, Schwartz M. Brain regeneration in physiology and pathology: the immune signature driving therapeutic plasticity of neural stem cells. Physiol Rev. 2011;91:1281-304.

3. Pluchino S, Cossetti C. How stem cells speak with host immune cells in inflammatory brain diseases. Glia. 2013;61:1379-401.

4. Uccelli A, Benvenuto F, Laroni A, Giunti D. Neuroprotective features of mesenchymal stem cells. Best Pract Res Clin Haematol. 2011;24:59-64.

5. Aharonowiz M, Einstein O, Fainstein N, Lassmann $H$, Reubinoff $B$, Ben-Hur T. Neuroprotective effect of transplanted human embryonic stem cell-derived neural precursors in an animal model of multiple sclerosis. PLOS ONE. 2008:3:e3145.

6. Einstein O, Karussis D, Grigoriadis N, Mizrachi-Kol R, Reinhartz E, Abramsky O, Ben-Hur T. Intraventricular transplantation of neural precursor cell spheres attenuates acute experimental allergic encephalomyelitis. Mol Cell Neurosci. 2003;24:1074-82.

7. Pluchino S, Quattrini A, Brambilla E, Gritti A, Salani G, Dina G, Galli R, Del Carro U, Amadio S, Bergami A, et al. Injection of adult neurospheres induces recovery in a chronic model of multiple sclerosis. Nature. 2003;422:688-94.

8. Pluchino S, Zanotti L, Brambilla E, Rovere-Querini P, Capobianco A, AlfaroCervello C, Salani G, Cossetti C, Borsellino G, Battistini L, et al. Immune regulatory neural stem/precursor cells protect from central nervous system autoimmunity by restraining dendritic cell function. PLoS One. 2009;4:e5959.

9. Pluchino S, Zanotti L, Rossi B, Brambilla E, Ottoboni L, Salani G, Martinello M, Cattalini A, Bergami A, Furlan R, et al. Neurosphere-derived multipotent precursors promote neuroprotection by an immunomodulatory mechanism. Nature. 2005;436:266-71.

10. Knight JC, Scharf EL, Mao-Draayer Y. Fas activation increases neural progenitor cell survival. J Neurosci Res. 2010;88:746-57.

11. Fainstein N, Vaknin I, Einstein O, Zisman P, Ben Sasson SZ, Baniyash M Ben-Hur T. Neural precursor cells inhibit multiple inflammatory signals. Mol Cell Neurosci. 2008:39:335-41.

12. Kim SY, Cho HS, Yang SH, Shin JY, Kim JS, Lee ST, Chu K, Roh JK, Kim SU, Park CG. Soluble mediators from human neural stem cells play a critical role in suppression of T-cell activation and proliferation. J Neurosci Res. 2009;87:2264-72

13. Pluchino S, Gritti A, Blezer E, Amadio S, Brambilla E, Borsellino G, Cossetti C, Del Carro U, Comi G, t Hart B, et al. Human neural stem cells ameliorate autoimmune encephalomyelitis in non-human primates. Ann Neurol. 2009;66:343-54.

14. Ricci-Vitiani L, Lombardi DG, Signore M, Biffoni M, Pallini R, Parati E, Peschle C, De Maria R. Human neural progenitor cells display limited cytotoxicity and increased oligodendrogenesis during inflammation. Cell Death Differ. 2007;14:876-8.

15. Cossetti C, Iraci N, Mercer TR, Leonardi T, Alpi E, Drago D, Alfaro-Cervello C, Saini HK, Davis MP, Schaeffer J, et al. Extracellular vesicles from neural stem cells transfer IFN-gamma via Ifngr1 to activate Stat1 signaling in target cells. Mol Cell. 2014;56:193-204.

16. Drago D, Cossetti C, Iraci N, Gaude E, Musco G, Bachi A, Pluchino S. The stem cell secretome and its role in brain repair. Biochimie. 2013;95:2271-85.

17. Ribeiro CA, Salgado AJ, Fraga JS, Silva NA, Reis RL, Sousa N. The secretome of bone marrow mesenchymal stem cells-conditioned media varies with time and drives a distinct effect on mature neurons and glial cells (primary cultures). J Tissue Eng Regen Med. 2011;5:668-72.

18. Salgado AJ, Gimble JM. Secretome of mesenchymal stem/stromal cells in regenerative medicine. Biochimie. 2013;95:2195.

19. Teixeira FG, Carvalho MM, Sousa N, Salgado AJ. Mesenchymal stem cells secretome: a new paradigm for central nervous system regeneration? Cell Mol Life Sci. 2013;70:3871-82.

20. Kokaia Z, Martino G, Schwartz M, Lindvall O. Cross-talk between neural stem cells and immune cells: the key to better brain repair? Nat Neurosci. 2012;15:1078-87.

21. Ratajczak MZ, Kucia M, Jadczyk T, Greco NJ, Wojakowski W, Tendera M, Ratajczak J. Pivotal role of paracrine effects in stem cell therapies in regenerative medicine: can we translate stem cell-secreted paracrine factors and microvesicles into better therapeutic strategies? Leukemia. 2012;26:1166-73

22. Ren G, Zhao X, Zhang L, Zhang J, L'Huillier A, Ling W, Roberts Al, Le AD, Shi S, Shao C, Shi Y. Inflammatory cytokine-induced intercellular adhesion molecule-1 and vascular cell adhesion molecule-1 in mesenchymal stem cells are critical for immunosuppression. J Immunol. 2010;184:2321-8.

23. Tran C, Damaser MS. Stem cells as drug delivery methods: application of stem cell secretome for regeneration. Adv Drug Deliv Rev. 2015;82-83:1-11.

24. Madrigal M, Rao KS, Riordan NH. A review of therapeutic effects of mesenchymal stem cell secretions and induction of secretory modification by different culture methods. J Transl Med. 2014;12:260.

25. Pawitan JA. Prospect of stem cell conditioned medium in regenerative medicine. Biomed Res Int. 2014;2014:965849.

26. Holmes E, Wilson ID, Nicholson JK. Metabolic phenotyping in health and disease. Cell. 2008:134:714-7.

27. Kaddurah-Daouk R, Kristal BS, Weinshilboum RM. Metabolomics: a global biochemical approach to drug response and disease. Annu Rev Pharmacol Toxicol. 2008;48:653-83.

28. Oldiges M, Lutz S, Pflug S, Schroer K, Stein N, Wiendahl C. Metabolomics: current state and evolving methodologies and tools. Appl Microbiol Biotechnol. 2007;76:495-511.

29. Shulaev $V$. Metabolomics technology and bioinformatics. Brief Bioinform. 2006;7:128-39.

30. Weckwerth W, Morgenthal K. Metabolomics: from pattern recognition to biological interpretation. Drug Discov Today. 2005;10:1551-8.

31. Nicholson JK, Connelly J, Lindon JC, Holmes E. Metabonomics: a platform for studying drug toxicity and gene function. Nat Rev Drug Discov. 2002;1:153-61.

32. Nicholson JK, Lindon JC. Systems biology: metabonomics. Nature. 2008;455:1054-6.

33. Pluchino S, Muzio L, Imitola J, Deleidi M, Alfaro-Cervello C, Salani G, Porcheri C, Brambilla E, Cavasinni F, Bergamaschi A, et al. Persistent inflammation alters the function of the endogenous brain stem cell compartment. Brain. 2008:131:2564-78.

34. Gonzalez-Perez O, Gutierrez-Fernandez F, Lopez-Virgen V, Collas-Aguilar J, Quinones-Hinojosa A, Garcia-Verdugo JM. Immunological regulation of neurogenic niches in the adult brain. Neuroscience. 2012;226:270-81.

35. Zimmermann JA, McDevitt TC. Pre-conditioning mesenchymal stromal cell spheroids for immunomodulatory paracrine factor secretion. Cytotherapy. 2014;16:331-45.

36. Lyons $A B$, Parish $C R$. Determination of lymphocyte division by flow cytometry. J Immunol Methods. 1994;171:131-7.

37. Bonnevier JL, Yarke CA, Mueller DL. Sustained B7/CD28 interactions and resultant phosphatidylinositol 3-kinase activity maintain G1->S phase transitions at an optimal rate. Eur J Immunol. 2006;36:1583-97.

38. Xia J, Mandal R, Sinelnikov IV, Broadhurst D, Wishart DS. MetaboAnalyst 2. 0 - a comprehensive server for metabolomic data analysis. Nucleic Acids Res. 2012;40:W127-33.

39. Bronte $V$, Zanovello P. Regulation of immune responses by L-arginine metabolism. Nat Rev Immunol. 2005:5:641-54.

40. Yu H, lyer RK, Kern RM, Rodriguez WI, Grody WW, Cederbaum SD. Expression of arginase isozymes in mouse brain. J Neurosci Res. 2001;66:406-22.

41. Dardalhon V, Korn T, Kuchroo VK, Anderson AC. Role of Th1 and Th17 cells in organ-specific autoimmunity. J Autoimmun. 2008;31:252-6.

42. Makridakis M, Roubelakis MG, Vlahou A. Stem cells: insights into the secretome. Biochim Biophys Acta. 1834;2013:2380-4.

43. Liu S, Liu D, Chen C, Hamamura K, Moshaverinia A, Yang R, Liu Y, Jin Y, Shi S. MSC transplantation improves osteopenia via epigenetic regulation of Notch signaling in lupus. Cell Metab. 2015;22:606-18.

44. Lee RH, Pulin AA, Seo MJ, Kota DJ, Ylostalo J, Larson BL, Semprun-Prieto L, Delafontaine P, Prockop DJ. Intravenous hMSCs improve myocardial infarction in mice because cells embolized in lung are activated to secrete the anti-inflammatory protein TSG-6. Cell Stem Cell. 2009;5:54-63.

45. McNamara LE, Sjostrom T, Meek RM, Oreffo RO, Su B, Dalby MJ, Burgess KE. Metabolomics: a valuable tool for stem cell monitoring in regenerative medicine. J R Soc Interface. 2012;9:1713-24.

46. Zamboni N, Sauer U. Novel biological insights through metabolomics and 13C-flux analysis. Curr Opin Microbiol. 2009;12:553-8.

47. Mussai F, De Santo C, Abu-Dayyeh I, Booth S, Quek L, McEwen-Smith RM, Qureshi A, Dazzi F, Vyas P, Cerundolo V. Acute myeloid leukemia creates an arginase-dependent immunosuppressive microenvironment. Blood. 2013; 122:749-58

48. Jenkinson CP, Grigor MR. Rat mammary arginase: isolation and characterization. Biochem Med Metab Biol. 1994;51:156-65.

49. Highfill SL, Rodriguez PC, Zhou Q, Goetz CA, Koehn BH, Veenstra R, Taylor PA, Panoskaltsis-Mortari A, Serody JS, Munn DH, et al. Bone marrow myeloid-derived suppressor cells (MDSCs) inhibit graft-versus-host disease 
(GVHD) via an arginase-1-dependent mechanism that is up-regulated by interleukin-13. Blood. 2010;116:5738-47.

50. Khaled YS, Ammori BJ, Elkord E. Myeloid-derived suppressor cells in cancer: recent progress and prospects. Immunol Cell Biol. 2013;91:493-502.

51. Rodriguez PC, Ernstoff MS, Hernandez C, Atkins M, Zabaleta J, Sierra R, Ochoa AC. Arginase I-producing myeloid-derived suppressor cells in renal cell carcinoma are a subpopulation of activated granulocytes. Cancer Res. 2009;69:1553-60.

52. Rodriguez PC, Quiceno DG, Zabaleta J, Ortiz B, Zea AH, Piazuelo MB, Delgado A, Correa P, Brayer J, Sotomayor EM, et al. Arginase I production in the tumor microenvironment by mature myeloid cells inhibits T-cell receptor expression and antigen-specific T-cell responses. Cancer Res. 2004; 64:5839-49.

53. Sahin E, Haubenwallner S, Kuttke M, Kollmann I, Halfmann A, Dohnal AM, Chen L, Cheng P, Hoesel B, Einwallner E, et al. Macrophage PTEN regulates expression and secretion of arginase I modulating innate and adaptive immune responses. J Immunol. 2014;193:1717-27.

54. Mussai F, Egan S, Hunter S, Webber H, Fisher J, Wheat R, McConville CM, Sbirkov Y, Wheeler K, Bendle G, et al. Neuroblastoma arginase activity creates an immunosuppressive microenvironment that impairs autologous and engineered immunity. Cancer Res. 2015;75:3043-53.

55. Xu L, Hilliard B, Carmody RJ, Tsabary G, Shin H, Christianson DW, Chen YH. Arginase and autoimmune inflammation in the central nervous system. Immunology. 2003;110:141-8.

56. Ahn M, Yang W, Kim H, Jin JK, Moon C, Shin T. Immunohistochemical study of arginase-1 in the spinal cords of Lewis rats with experimental autoimmune encephalomyelitis. Brain Res. 2012;1453:77-86.

57. Carmody RJ, Hilliard B, Maguschak K, Chodosh LA, Chen YH. Genomic scale profiling of autoimmune inflammation in the central nervous system: the nervous response to inflammation. J Neuroimmunol. 2002;133:95-107.

58. Zhou L, Sun CB, Liu C, Fan Y, Zhu HY, Wu XW, Hu L, Li QP. Upregulation of arginase activity contributes to intracellular ROS production induced by high glucose in H9c2 cells. Int J Clin Exp Pathol. 2015;8:2728-36.

59. Halaris A, Plietz J. Agmatine: metabolic pathway and spectrum of activity in brain. CNS Drugs. 2007;21:885-900.

\section{Submit your next manuscript to BioMed Central and we will help you at every step:}

- We accept pre-submission inquiries

- Our selector tool helps you to find the most relevant journal

- We provide round the clock customer support

- Convenient online submission

- Thorough peer review

- Inclusion in PubMed and all major indexing services

- Maximum visibility for your research

Submit your manuscript at www.biomedcentral.com/submit 